University of Redlands

\title{
The City of Riverside Food System Map and Healthy Food Accessibility Analysis
}

\author{
A Major Individual Project submitted in partial satisfaction of the requirements \\ for the degree of Master of Science in Geographic Information Systems \\ by \\ Josphat Mutunga
}

Nader Afzalan, Ph.D., Committee Chair

Douglas Flewelling, Ph.D.

August 2017 
The City of Riverside Food System Map and Healthy Food Accessibility Analysis

Copyright @ 2017

by

Josphat Mutunga 
The report of Josphat Mutunga is approved.
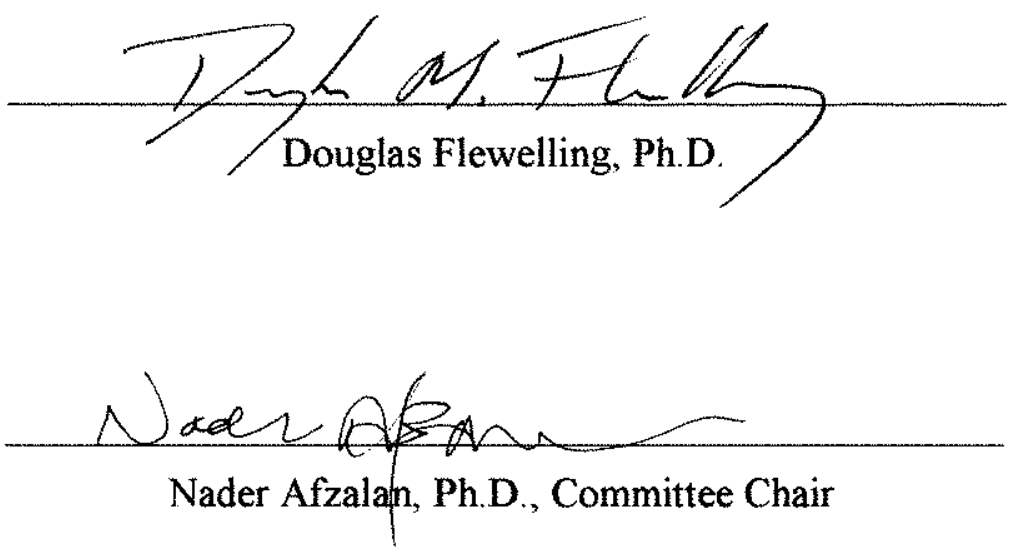

August 2017 



\section{Acknowledgements}

What an incredible journey! I am thankful to the Almighty God for strength and grace to accomplish my master's degree. This would not have been possible without the financial support of the Morrison Family Trust and Esri/Dangermond Fellowships. I am deeply grateful.

Many thanks to my advisor, Afzalan Nader. I couldn't have asked for a better person to lead me through the rocky journey of a MIP. You were understanding, kind, supportive, professional, and allowed me freedom and space to enjoy the challenge when I needed it. You helped me a lot both academically and professionally and I appreciate it. Thanks to Andrea, the MS GIS faculty and cohort 30 for all the support you granted me in completing this program. Thanks to Mathew Flewelling for helping with my code and all the advice. Everyone played a role in shaping my path.

Thank you, Joseph and Victoria, for walking with me through this journey. When it was tough, you encouraged me that it was going to be okay. I bless you for your help and support in my studies as well as during my stay in the US.

To mum and dad for supporting me this far. I honor you for raising and preparing me properly early in my life to be able to take on challenges such as this program without fear. May God keep you in good health and happiness be your portion.

To my fiancé, Mercy Chamia, the love and rock of my life, I cannot thank you enough. You were interested every day in my progress which meant you walked with me every step of the way. Despite the distance apart, you made it easy for me. You were selfless and allowed me peace of mind and all the support I needed as my closest friend to focus on my project. I love you. 



\begin{abstract}
The City of Riverside Food System Map and Healthy Food Accessibility Analysis by Josphat Mutunga

Food security is a component of both accessibility and nutritional value of food to the consumer. Food access is dependent on income and the distance a consumer covers to get to a food source. Healthy food access is therefore both a geographical and socioeconomic problem. In this project, the City of Riverside sought GIS technology to understand and tackle issues related to healthy food access. This was achieved through the development of an online application that maps local food resources and spatial analysis to investigate food access in relation to the spatial distribution of these resources. Income levels and distance from a food source were the criteria used to identify areas in the city that have low healthy food access and require attention by policy makers and other stakeholders. The results of the food analysis were communicated through the web application. The application is also an interactive platform that consumers and food distribution sources could use to connect with each other.
\end{abstract}





\section{Table of Contents}

Chapter 1 - Introduction .........................................................................................................1

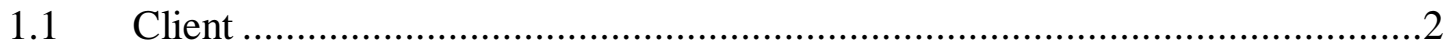

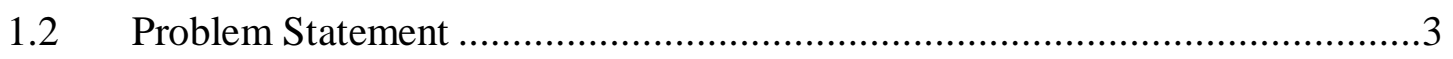

$1.3 \quad$ Proposed Solution ...................................................................................

1.3.1 Goals and Objectives ......................................................................

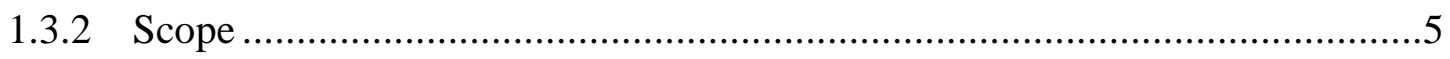

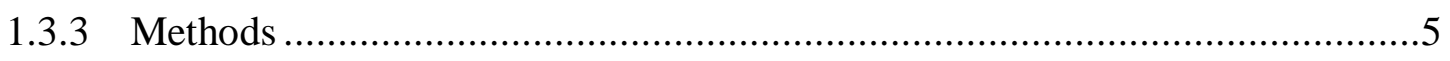

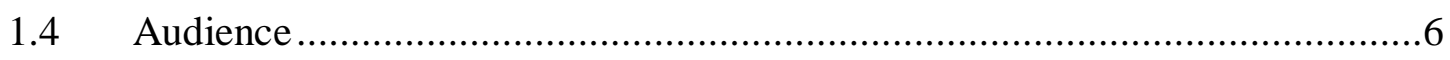

1.5 Overview of the Rest of this Report..........................................................

Chapter 2 - Background and Literature Review .................................................................7

$2.1 \quad$ Local Food Systems …………………................................................

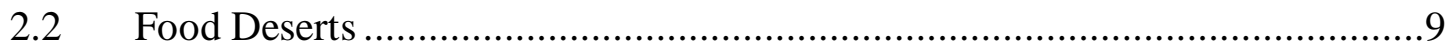

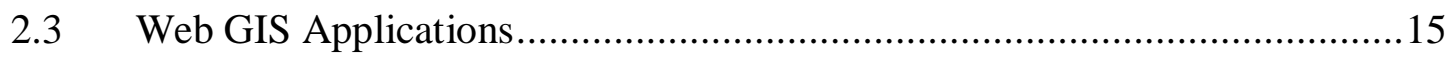

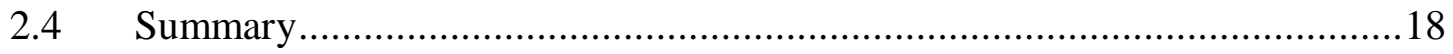

Chapter 3 - Systems Analysis and Design ......................................................................21

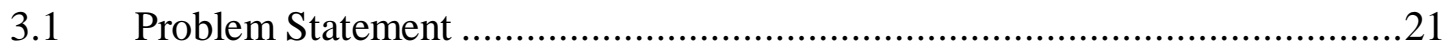

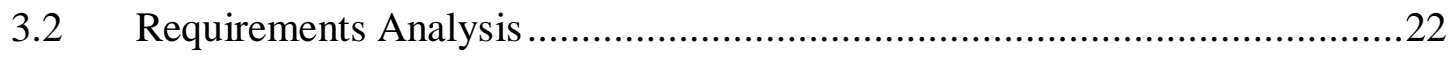

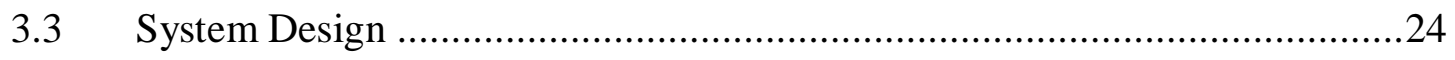

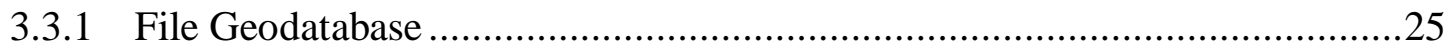

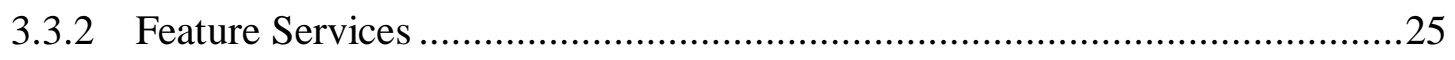

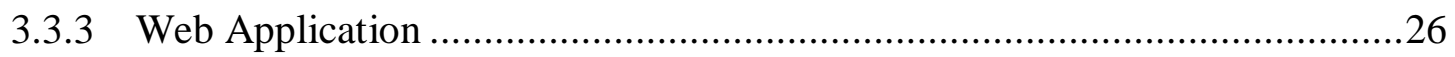

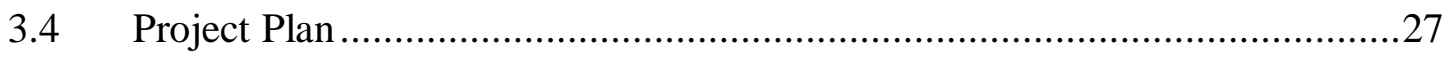




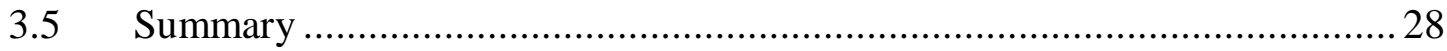

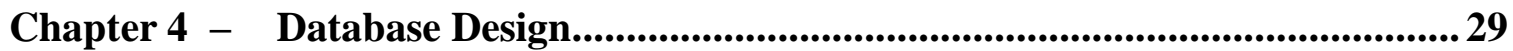

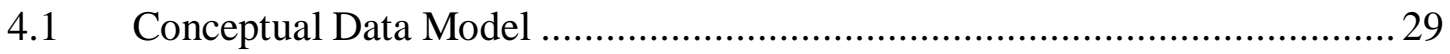

4.2 Logical Data Model ............................................................................... 31

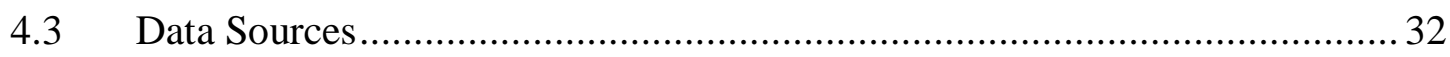

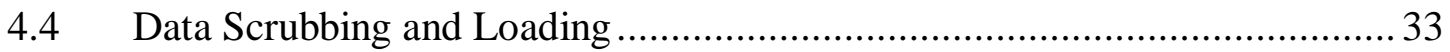

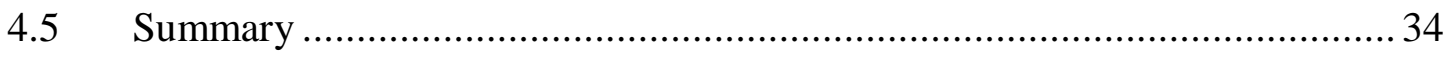

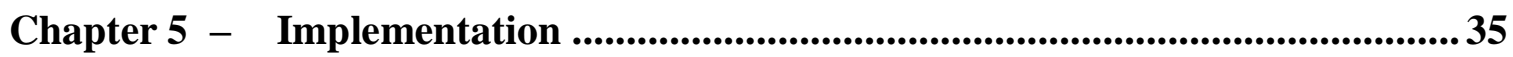

5.1 Spatial Analysis to Identify Food Deserts..................................................... 35

5.2 Preparing the Food Resources Map Document ............................................... 43

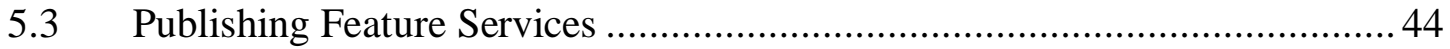

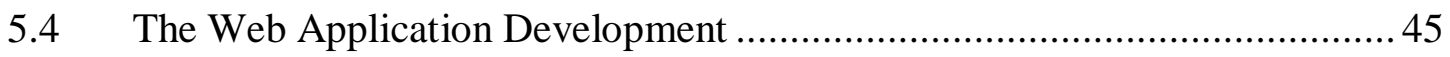

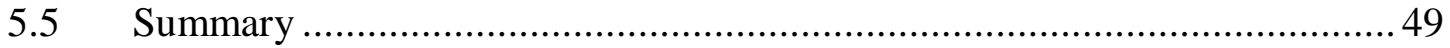

Chapter 6 - Results and Analysis................................................................................551

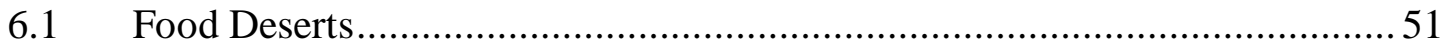

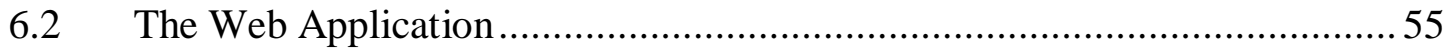

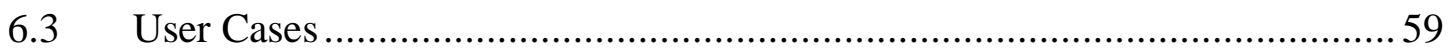

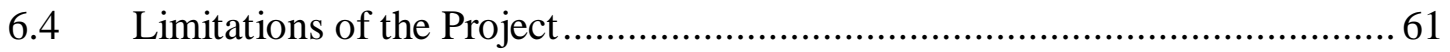

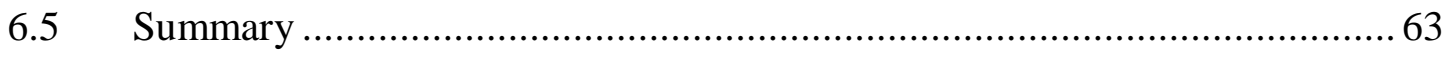

Chapter 7 - Conclusions and Future Work ……………………........................................6 65

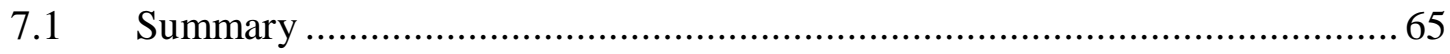

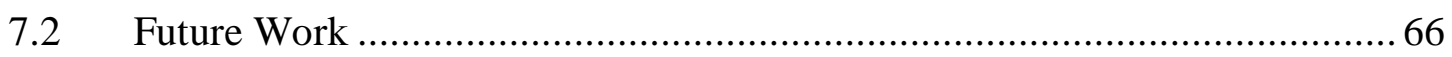


Works Cited

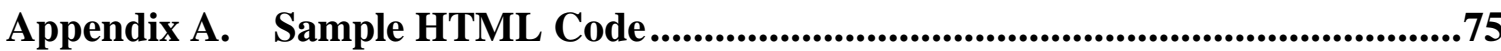

Appendix B: Maps ......................................................................................................................77 



\section{Table of Figures}

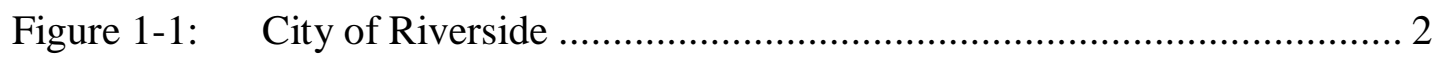

Figure 2-1: $\quad$ USDA Low Income and Low Access at 1 Mile (Data Source: USDA

Economic Research Service) .................................................................... 12

Figure 2-2: $\quad$ USDA Low Income and Low Access at 0.5 mile (Data Source:

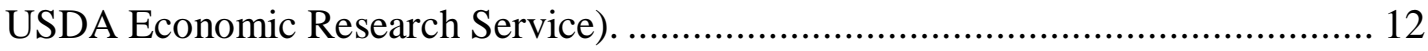

Figure 2-3: KYF Compass Map Displaying USDA Programs Related to Local

Food Systems in California [url:https://www.usda.gov/wps/ portal/usda/usdamedia?

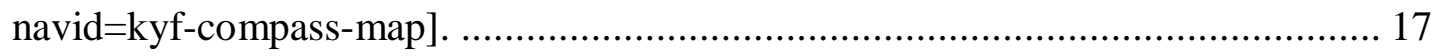

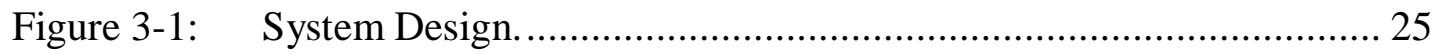

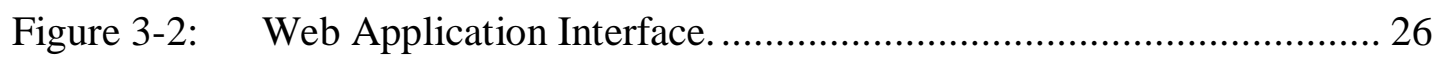

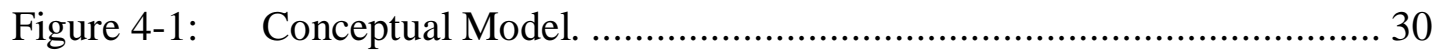

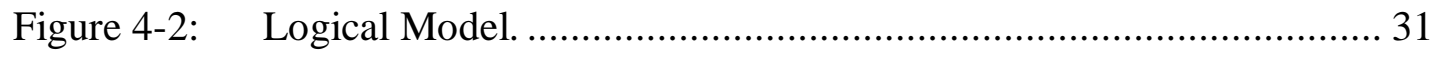

Figure 5-1: Areas Serviced by Healthy Food Sources within 500M Distance. ... 38

Figure 5-2: $\quad$ Areas Serviced by Healthy Food Sources within 500M Distance. ... 39

Figure 5-3: $\quad$ Logical Block Group 06065031031 and 6065031032 Population with

Access to Healthy Food Source is $49.7 \%$ and $36.2 \%$ Respectively...................... 40

Figure 5-4: Block Groups with Low Food Access ..................................... 42

Figure 5-5: $\quad$ Riverside Food Deserts....................................................... 42

Figure 5-6: $\quad$ Riverside Food Sources. .......................................................... 44

Figure 5-7: The Service Editor Menu in ArcMap. ...................................... 45

Figure 5-8: The User Interface of the Web Application............................... 48

Figure 5-9: The Information Window (Pop-up) Showing Feature Attributes. .... 49 
Figure 6-1: The Overlay of USDA Low Income (LI) \& Low Access (LA) Census Tracts (green) and Riverside Low Food Access (red) Analysis Results. Data Source:

USDA Economic Research Service................................................................ 52

Figure 6-2: $\quad$ City Residents Affected by Food Deserts.................................. 53

Figure 6-3: Households Living in Food Deserts.......................................... 55

Figure 6-4: The Existing Static Riverside Food System Map......................... 57

Figure 6-5: Application Interface Showing Accordion Menu and Other Features. 58

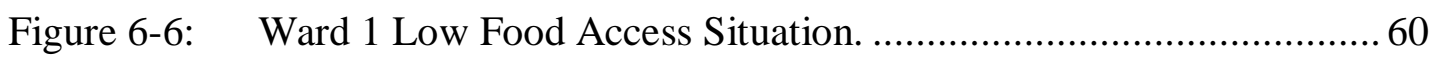

Figure 6-7: $\quad$ Pop-up Window Providing Key Non-Spatial Information to a User. 61 


\section{List of Tables}

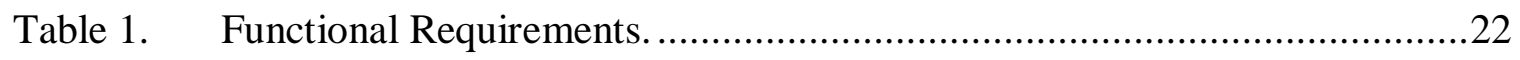

Table 2. Non-functional Requirements. ......................................................24

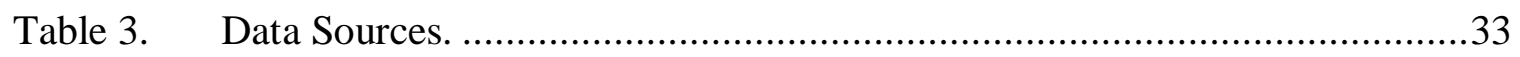





\section{List of Acronyms and Definitions}

AGOL ArcGIS Online

ACS American Community Survey

API Application Programming Interface

CSS Cascading Style Sheet

CSV Comma Separated Values

HEAL Healthy Eating Active Living

HTML Hyper Text Markup Language

HTTP Hypertext Transfer Protocol

JS JavaScript

JSON JavaScript Object Notation

IDE Integrated Development Environment

Mac OS Macintosh Operating System

PARC Xerox Corporation Palo Alto Research Centre

REST Representational State Transfer

SaaS Software as a Service

SNAP Supplemental Nutrition Assistance Program

TEFAP The Emergency Food Assistance Program

URL Universal Resource Locator

USDA United States Department of Agriculture

WIC Women Infants, and Children

XML Extensible Markup Language

ZIP Zone Improvement Plan 
xviii 


\section{Chapter 1 - Introduction}

In 2010, while launching USDA's five-year strategic plan, Agriculture Secretary Tom Vilsack reiterated the government's commitment, "to develop and revitalize the critical infrastructure necessary for vibrant food systems" (USDA, 2009, p 6). The USDA has since developed an interactive web map application to visualize 25 programs associated with promoting local food systems (https://www.usda.gov/wps/portal/usda/usdamedia? navid=kyf-compass-map). Following the USDA's lead, the City of Riverside has taken up the challenge to develop its own local food system to increase food accessibility. Local food systems play a critical role in improving access to food, especially locally produced (Walker, Keane \& Burke, 2010). Impediments to food accessibility include household or individual income and distance from a store that stocks fresh food. USDA describes food deserts as areas inhabited mostly by socio-economically challenged people facing limited access to fresh food due to the absence of healthy food sources such as supermarkets and local farmers markets (USDA, 2010).

Through the creation of a web application, this project was intended to spark genuine interest among consumers their food sources. Mapping this information and conducting spatial analysis using food source and demographics data will help the city to make informed decisions to feed its steadily growing population of 324,696 through entirely locally produced fresh food (California Department of Finance, 2016). This project also focusses on identifying food deserts to inform policy makers and nongovernmental organizations that champion the accessibility of healthy nutrition. The City of Riverside Agricultural Development Department coordinated by Joyce Jong intended to use these results to narrow the focus to areas that need urgent attention to improve food 
accessibility through soliciting for grants to benefit these areas, offering incentives to potential business owners willing to invest in food stores in these areas among others. Figure 1.1 shows the geographical location of the City of Riverside.

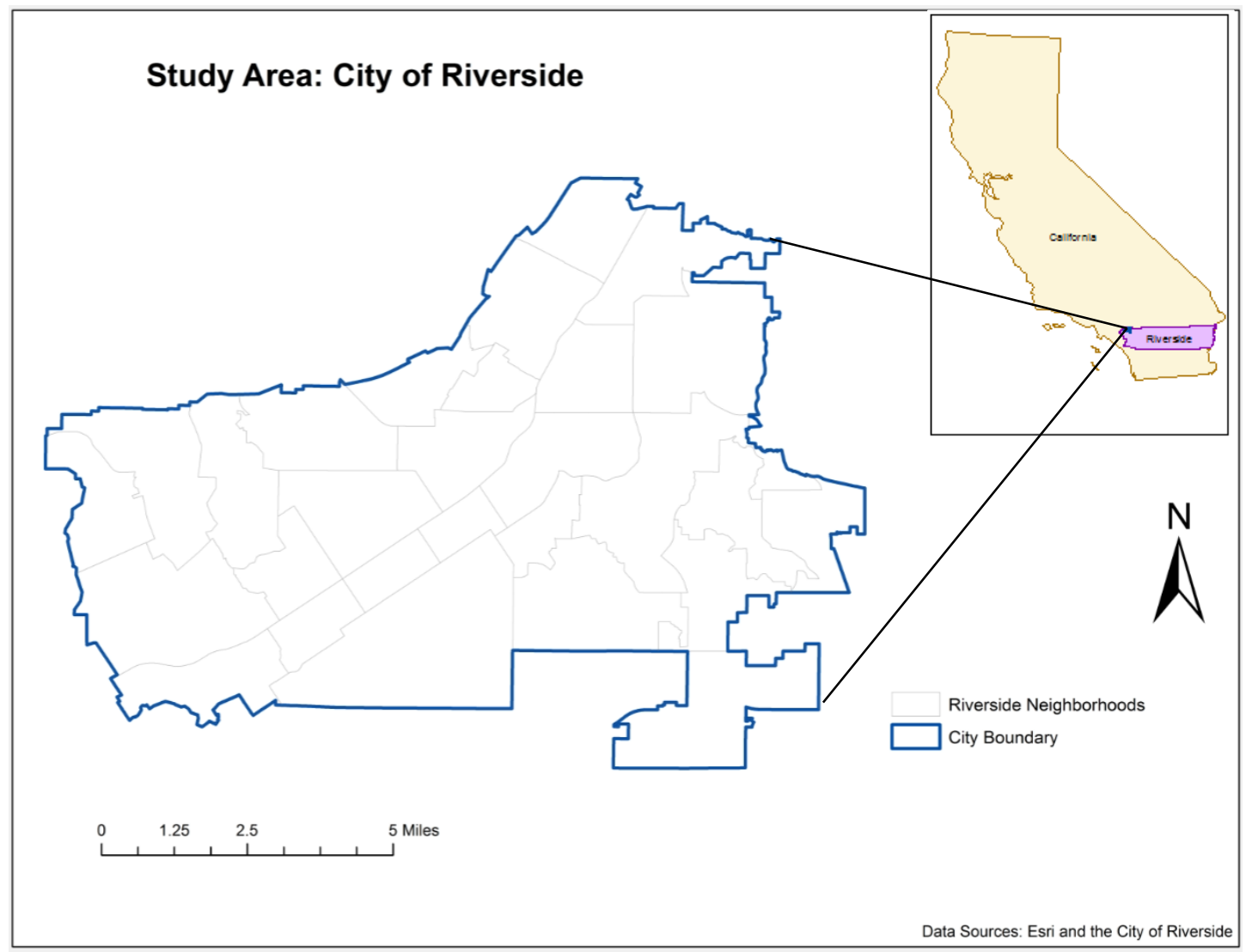

\section{Figure 1-1: City of Riverside}

\subsection{Client}

The client for this project was the City of Riverside. The contact persons were Joyce Jong, Agriculture Business Development Coordinator for the Economic Development Division, and Lisa A. Pierce, GIS Analyst for the City of Riverside, Innovation, and Technology Division. As the chief coordinator in the Agriculture and Business Development department, Ms. Jong oversees and coordinates programs, community initiatives, forums, etc. that bring together agricultural stakeholders to spur local food 
production and consumption. The Community and Economic Development mandate inspire these activities to provide an enabling business environment and necessary resources. Ms. Pierce's GIS department works together with other departments to integrate GIS in their service delivery to city residents. The clients provided data and technical guidance during the execution of the project.

\subsection{Problem Statement}

With the advent of myriad lifestyle diseases, enhancing the accessibility of fresh food has become a key goal for policy makers and administrators in the city of Riverside. The city is also increasingly interested in developing a strong local food system that not only meets the nutritional needs of its population, but also supports the local economy and contributes to decreased carbon emissions from fossil fuel consumption during food transportation (Galzki, Mulla, \& Peters, 2014). A viable local food system also tends to favor socioeconomically challenged city residents, as small local stores located within short distances from the farm offer low prices compared to bigger stores located further away from the production areas. Consumers are also interested in knowing where their food comes from, and the methods used during farming. They are willing to pay more to local producers who use environmentally friendly methods of agriculture (USDA, 2009).

There is substantial interest by the city administration, food producers, and consumers that has led to an intriguing conversation around strengthening the local food system. Food deserts remain a bottleneck towards making fresh food readily accessible, especially low-income earners. Therefore, an effective method to identify and inform relevant food stakeholders about the existence of food deserts is crucial. 


\subsection{Proposed Solution}

The proposed solution for this project is to develop a web mapping application to serve as an information platform to facilitate interaction and decision making among food stakeholders (Tomlinson, 2013). The web map application is a repository for all food stores and analysis maps showing food accessibility trends within the City of Riverside.

The web mapping application is expected to stimulate a meaningful communication channel among city residents in their quest to achieve a self-sustaining local food system. Through the application, food stakeholders would locate local stores and farms that provide food within their neighborhood. The city administration would also benefit from the proposed web tool as a visualized platform to identify opportunities and areas of focus to strengthen the local food system and make healthy food more accessible.

\subsubsection{Goals and Objectives}

The main goal of this project was to increase healthy food accessibility and revitalize a sustainable local food system for the City of Riverside by creating an interactive map of food resources. The main objective was to configure an interactive web mapping application containing food source data and embed it in the city's official website to enable food stakeholders like growers and consumers to interact, locate food stores of interest, and improve expenditure on locally produced food. Analysis maps were also produced to locate areas within the city faced with low healthy food accessibility. The first objective was to create a file geodatabase using ArcCatalog to store all the data consumed by the web application. The second objective was to configure an interactive web application to visualize all local food stores and resources in the City of Riverside. 
The third objective was to carry out spatial analysis to identify food deserts and accessibility patterns in the City. Finally, food resources, food desert, and accessibility maps were authored as crucial sources of information for decision making by city administrators.

\subsubsection{Scope}

The project scope for this project was the delivery of three information products to the client: a file geodatabase, food desert and food accessibility maps, and a web application that consumed all the authored maps. The web application holds all food resources within the City of Riverside. The Riverside Food System Map, as the main web app, provides an interactive platform for local food growers and consumers to encourage food accessibility and distribution. The file geodatabase holds all the data used for analysis, and authored feature services for consumption by the web application. The food desert and food accessibility maps were created to inform policy makers and non-governmental institutions and facilitate decision making.

\subsubsection{Methods}

The web mapping application was configured using ArcGIS API for JavaScript, HTML5, and CSS. Vector data displayed on the web application were called through the ArcGIS Server REST URLs of feature services published to ArcGIS Online. The application code was developed using JetBrains WebStorm 2016.3.3 IDE version. The file geodatabase and all GIS data preparation activities were performed using ArcCatalog. Weighted overlay and Origin-Destination (OD) cost matrix analyzes were used to identify food deserts and accessibility patterns. Other maps used for this project were created using ArcGIS software and ArcGIS Online environment provided by the Esri. 


\subsection{Audience}

The audience for the project's information products included food growers, consumers, policy makers, and other relevant food stakeholders in the City of Riverside. The easy-touse web application was configured to provide a positive interactive experience for users with little knowledge of GIS, and experienced GIS professionals.

\subsection{Overview of the Rest of this Report}

Chapter Two is a literature review of previous research regarding local food systems, food deserts, and GIS web mapping technologies. Chapter Three tackles the project requirements, the main project components, and the project execution plan report. Chapter Four describes the data, data models, and methods used to clean and prepare the project data. Chapter Five lays out the implementation process to meet the client's requirements. Chapter Six details the analysis results. Chapter Seven describes the conclusions of the project and possibilities for future work. 


\section{Chapter 2 - Background and Literature Review}

This chapter is a literature review of previous research conducted on three main topics of this project: local food systems, food deserts, and Web GIS. Section 2.1 examines the application of GIS technology to help improve food accessibility by empowering local food production and distribution. Section 2.2 discusses food deserts as a limitation to healthy food access and research methods applied to identify and communicate them to policy makers and other stakeholders interested in providing solutions. Section 2.3 introduces the concept of Web GIS as a tool used by organizations such as local governments to involve communities and policy makers in solving geospatial issues such as low food access in socio-economically challenged communities. Finally, section 2.4 offers a conclusion of the chapter.

\subsection{Local Food Systems}

A food system is a network that encompasses activities involved in the production, distribution, processing, and consumption of nutrient-sufficient foods (Hannah et al., 2012). The interaction of these activities together with the environment and communities contribute to food security. A broader definition of food system must therefore incorporate the impacts its activities have on the environment and the community. The economic, social, and environmental outcomes of the process of food production to consumption are therefore part of a food system (Ericksen, 2008). It is therefore not enough to produce food to meet the demand. Sustainability in all activities within a food system is a fundamental factor. A food system can be local, national, or even global depending on the geographical extent within which the interaction of its components occurs. 
Many cities in the United States have turned to local food systems to achieve selfsustainable fresh food production that can contribute to feeding the local population. According to Martinez et al., (2008), food is considered "local" if it is consumed within a short distance of its point of origin. To eliminate the ambiguity of this definition, the 2008 Farm Act states that a local product must have been produced not more than 400 miles before consumption (Senate Bill 6124 (2008)). This geographic limitation forces producers to rely heavily on a small market share. In a local food system, the producer often combines the roles of storage, processing, and marketing. The United States Department of Agriculture leaves the door open for a community to adopt a suitable definition based on its preferred marketing strategies. For example, a non-profit organization known as the Local Food Hub in Charlottesville, Virginia, buys local agricultural products and distributes to local consumers (USDA, 2009). The spatial context of a local food system makes it suitable as a target for the application of GIS.

A study was carried out in southeastern Minnesota to analyze the capacity of a local food system to feed eleven counties using GIS technologies. The study examined "an alternative land-use scenario to illustrate how better-utilizing land resources can yield environmental benefits" (Galzki, Mulla, \& Peters, 2014, p.1). Galzki, Mulla and Peters used a food-shed concept analogous to watersheds to establish the spatial extent by mapping all agricultural resources with a potential to feed the entire region. In this study, economic factors drove the movement of food units the same way obstacles shape the direction water follows down a river. Results showed that mapped agricultural resources had the capacity to feed the region's population of 500,000 people. The study model also 
established that a food unit would be transported six miles $(9.4 \mathrm{~km})$ if produced through annual agriculture and 14 miles $(22.3 \mathrm{~km})$ if perennially produced. Compared to the average national distance of 100 miles that a food unit is transported, these results were an encouragement for local policy makers and local food system crusaders.

In 2010, study was carried out in Toledo, Ohio to quantify food accessibility and the role of urban planning on Toledo's local food system (Eckert \& Komuniecki, 2010). The researchers relied on GIS to discover that urban planners have a key role in the development of sustainable local food system through proposing and implementing plans that favor the interaction of producers and consumers. According to the research, planners can use zoning as a tool to preserve farmland, permit turning vacant lots into agricultural land, protect small local agricultural businesses from being driven out of the market by large stores, establish a transport network that links neighborhoods to agricultural resources, and promote environmental conservation through prudent plans that cushion agricultural land, soil, and water from degradation.

\subsection{Food Deserts}

Local food markets play a critical role in meeting demand and accessibility of healthy foods. However, access to food is also linked to other factors, such as economic status, distance from a food source, and mobility of consumers. GIS technology has been instrumental in combining these impediments to food access to identify areas of low access, commonly referred to as food deserts.

USDA describes food deserts as areas inhabited mostly by socio-economically challenged people facing limited access to fresh food due to the absence of healthy food sources such as supermarkets and local farmers markets (USDA, 2010). According to 
Beaulac, Kristjansson, and Cummins (2009), the food desert problem goes beyond the availability of food suppliers. They suggested that the problem is linked to affordability, health of the food, and socio-economic disparities in the population. Therefore, the interaction of spatial and non-spatial factors such as poverty determine the accessibility of healthy food (Wang and Luo, 2005).

USDA (2011) created a web tool known as the Food Desert Locator to identify areas in the US that face limited access to healthy food. The goal of this project was to promote efforts by the government and other stakeholders that increase healthy food access in impoverished parts of the country. The following criteria were used to determine if an area, defined by census tract, was a food desert or not:

- $20 \%$ or more of the residents in a census tract live below poverty level,

- The median household/family income in a potential food desert tract must be $80 \%$ or less of the larger area's household median income, and,

- $33 \%$ of the population in the tract or 500 residents or more do not have access to a supermarket within one-mile distance. The same applied to rural areas but the distance applied was 10 miles.

The results of this model established that 13.5 million Americans have limited access to healthy food sources with $82 \%$ of them living in urban areas (USDA, 2011). Figure 2-1 shows food deserts identified using the above criteria in the City of Riverside. The green census tracts have both Low Income(LI) and Low Access (LA) hence food deserts (Ploeg $\&$ Rhone, 2017). Figure 2-2 represents food deserts identified in the City of Riverside when the distance to a supermarket was reduced to half a mile. This map indicates that more areas were classified as food deserts when the distance to a food source was 
reduced from one mile to half a mile. Similarly, a large area such as a census tract flattens data across the entire spatial analysis area unit (Ali et al., 2005). In figure 2-1, the generalization of income and access data over a census tract revels fewer food deserts than if block groups were to be used. The number of census tracts identified as food deserts increases when the distance to a food source used was 0.5 miles as shown in figure 2-2. This poses an important challenge in determining the appropriate analysis units and distance to a food source in food desert research and studies.

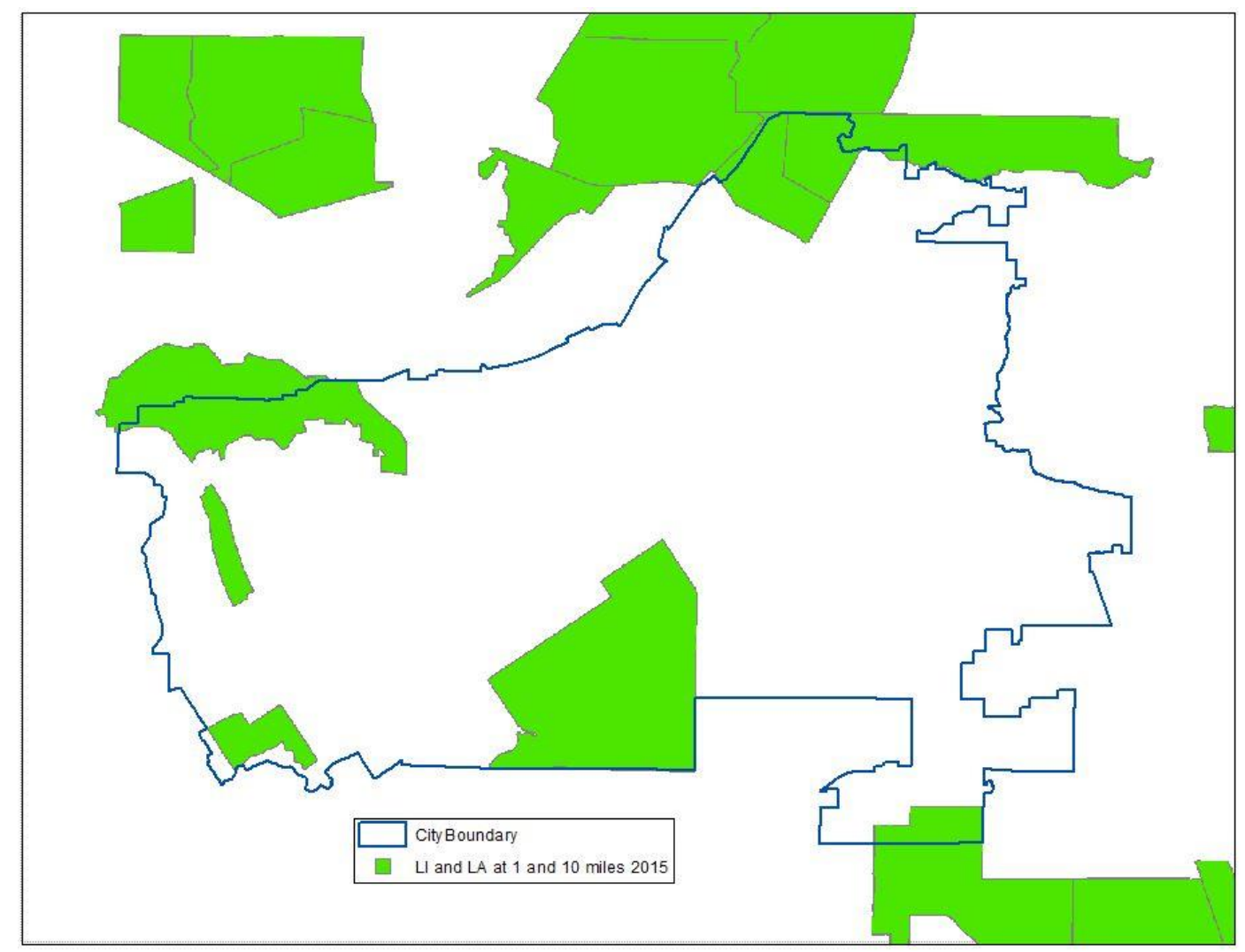




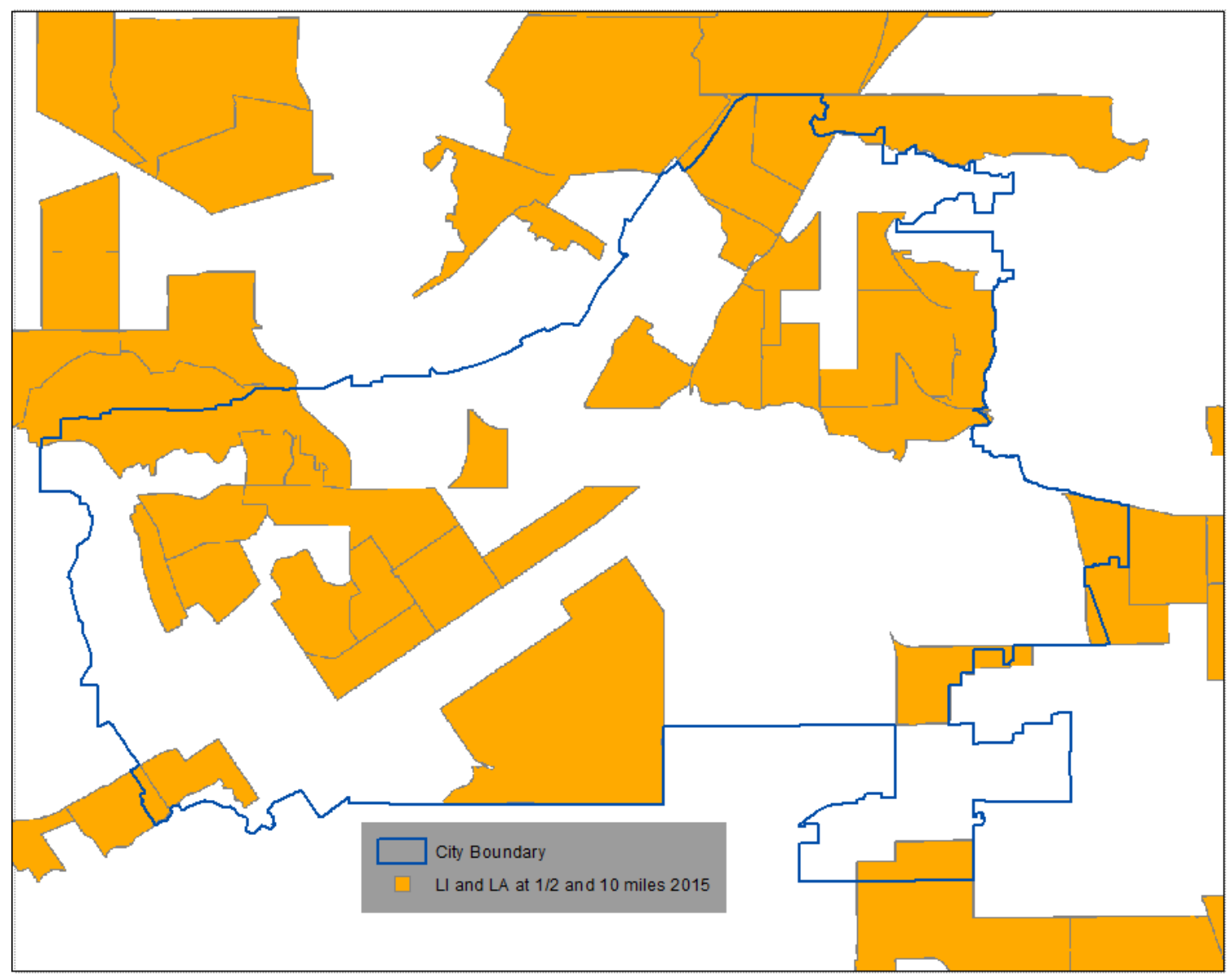

Figure 2-1: USDA Low Income and Low Access at 1 Mile (Data Source: USDA Economic Research Service).

Figure 2-2: $\quad$ USDA Low Income and Low Access at 0.5 mile (Data Source: USDA Economic Research Service).

According to Jiao et al (2012) food desert analyses using census block groups yield more reliable outcomes. This also improves accuracy and reliability of analysis results. They also noted the lack of a standard distance threshold for determining the limit when assessing food access in a neighborhood. Hallet IV \& McDermott (2010) suggest that most regions at the start of the 1990s used 500-meter radius as threshold to determine low food access when the phrase 'food desert' was introduced in academia in Western Scotland. Huang \& Pike (2016) also belief that modern urban development should ensure 
that every resident in a neighborhood should have access to five crucial facilities including food stores within a 500-metre radius.

Studies conducted on various disciplines have concluded that neighborhood design has a direct influence on access to facilities such as hospitals, food stores, schools, etc. Indicators of walkability such as mixed land use in a neighborhood influence access to these facilities (Spence, Cutusu, Edwards \& Evans, 2008). In their study to link neighborhood design and accessibility of recreational facilities with obesity, Spence et al. (2008) deduced that school children were more likely to engage in physical activity if a recreational facility was located within a walking distance.

Eckert \& Komuniecki (2010) used GIS analysis in their research to measure fresh food accessibility from local stores and markets. Using statistical analysis and other spatial analysis tools in ArcMap, they could overlay relevant datasets such as demographic data and census block group data to visualize existing patterns pertaining to the status of food flow. The Network Analyst tool was also instrumental in the research to establish the distance and time a consumer would take to access the closest store.

However, this analysis did not account for the travel time and distance that a consumer would be forced to cover to acquire food from more than one store in one trip. Results of Eckert \& Komuniecki's research showed that there was a $14.7 \%$ relationship between a nonlocal store and income levels and $7.3 \%$ between accessibility to a nearby store and income levels. Further, while using a one-mile buffer distance from each fresh food store, it was established that Toledo's grocery store distribution was not balanced, especially in socioeconomically challenged communities. 
Kuai and Zhao (2017) argued that proximity to food stores alone cannot be used to determine food accessibility. They stated that consumers preferences for certain food stores and store capacity are intrinsic variables that determine food accessibility. One way to address this caveat is to apply research methods that compute the ratio of food suppliers to the total population within a selected administrative boundary (Michimi \& Wimberly, 2010). Dai and Dang's 2011 study of the competitive aspect of food accessibility, whereby food resources share a common market within neighboring localities, was the basis for Luo and Wang's 2013 two-step floating catchment area (2SFCA) criteria for spatial analysis to investigate food distribution and consumption in areas where proximal neighborhoods share food resources.

In recent years, there have been many methods developed to measure food accessibility and literature to back up applied logic. Kuai and Zhao (2017) noted that these research methods appeared to ignore how consumers reach food resources. They stated that individuals who do not own a car may resort to eating unhealthy food linked with lifestyle diseases such as obesity and diabetes. This situation is exacerbated if accessibility is beyond walking distance in areas where public transport is non-existent. In Baltimore, Maryland, a spatial analysis to identify food deserts used quarter-mile distance from to a supermarket (Johns Hopkins Centre for a Livable Future, 2017).

Generally, there limitations exist pertaining methods used to locate food deserts. First, there is no consensus among researchers about the definition of limited access to healthy food (Ploeg, Dutko \& Breneman 2014). This loophole has led to limited focus of food desert studies to proximity to food sources and the ability to reach and purchase. Second, food desert identification does not pay attention to individuals leading to missed 
opportunity to identify correctly where to find individuals lacking food access. It is therefore possible to find people who cannot afford to access healthy food in rich neighborhoods and vice versa. Despite these limitations, existing methods have played a crucial role in recent years to promote healthy food access in the United States.

\subsection{Web GIS Applications}

At Web-based geospatial applications offer an alternative to organizations to communicate spatial information to communities. Since the invention of the first mapping web application by the Xerox Corporation Palo Alto Research Centre (PARC) in 1993, Web GIS has made great strides as a platform used by organizations to engage the public and aid policy makers in their decision-making process (Fu, 2016). $\mathrm{Fu}$ attributed the progressive success of Web GIS to the Internet and the World Wide Web as invented in the late 1960s and early 1990s respectively. He noted that the main advantages offered by Web GIS include: the ability to create apps usable across many platforms such as Windows and Mac OS, scalability of cloud capabilities to reach many users at once, intuitiveness of the applications, and low user and maintenance costs.

Web GIS enables organizations to harness the power of web Software as a Service (SaaS) by hosting GIS data in the cloud and retrieving them through GIS tools (Fu \& Sun, 2011). According to Fu and Sun this platform involves a server and a client or user. The user communicates with the server through a Uniform Resource Locator (URL) by pushing requests using Hypertext Transfer Protocol (HTTP). Fu and Sun wrote that the server response is processed through the same route by sending back a response in the form of HyperText Markup Language (HTML), Extensible Markup Language (XML) or JavaScript Object Notation (JSON) formats. The most widely used web service 
communication link is the Representational State Transfer (REST) (Fu, 2016). REST URL is used to call JavaScript Object Notation (JSON) such as hosted map layers for display on a web browser or application (Fu, 2016). This back-end communication between the server and the client offers various visualization capabilities of data.

Persaud (2013) who created a web application to track community health identified performance issues as the main impediment to the use of Web GIS. He suggested three ways of alleviating this issue based on application needs and resources. They include: Thin Client/ Thick Server, Thick Client/ Thin Server, and Medium Client and Server (Alesheikh et al, 2002). In Thin Client/ Thick Server architecture, all the load of processing the data is on the server with the web browser or client only displaying the results. On the other hand, in Thick Client/ Thin Server, processing occurs on the user end while the server provides the required data. Medium Client and Server tries to balance the other two methods where there is equal load demand between the client and the server.

Web GIS has been used to address food accessibility and productivity issues in the world today. Using accurate imagery data, impoverished areas around the world affected by low accessibility to food and acute famine can be identified and the information relayed to aid organization for appropriate action (Collett, 2014). Collette reported that the Consultative Group on International Agriculture Research (CGIAR) successfully created a web application of Roots, Tubers, and Bananas (RTB) maps in an initiative to identify and channel support aimed at increasing food production in areas with acute low access. The three crop types were identified as suitable for less productive parts of the world. RTB online maps enable users to overlay various layers including 
socio-economic data to investigate underlying information about these areas. This application also leverages the massive information content available in social media to collect more information in these areas for researchers and decision-makers.

In 2009, the USDA launched the Know Your Farmer, Know Your Food (KYF) initiative to revitalize local and regional food systems. This initiative includes the KYF Compass and KYF Map. The KYF Compass is an online documentation of USDA resources, programs, and projects associated with Local Food Systems (USDA, 2009). On the other hand, the KYF Map complements the KYF Compass by visualizing 27 selected programs across the United States that empower local farmers and agricultural businesses as shown in figure 2.1 below.

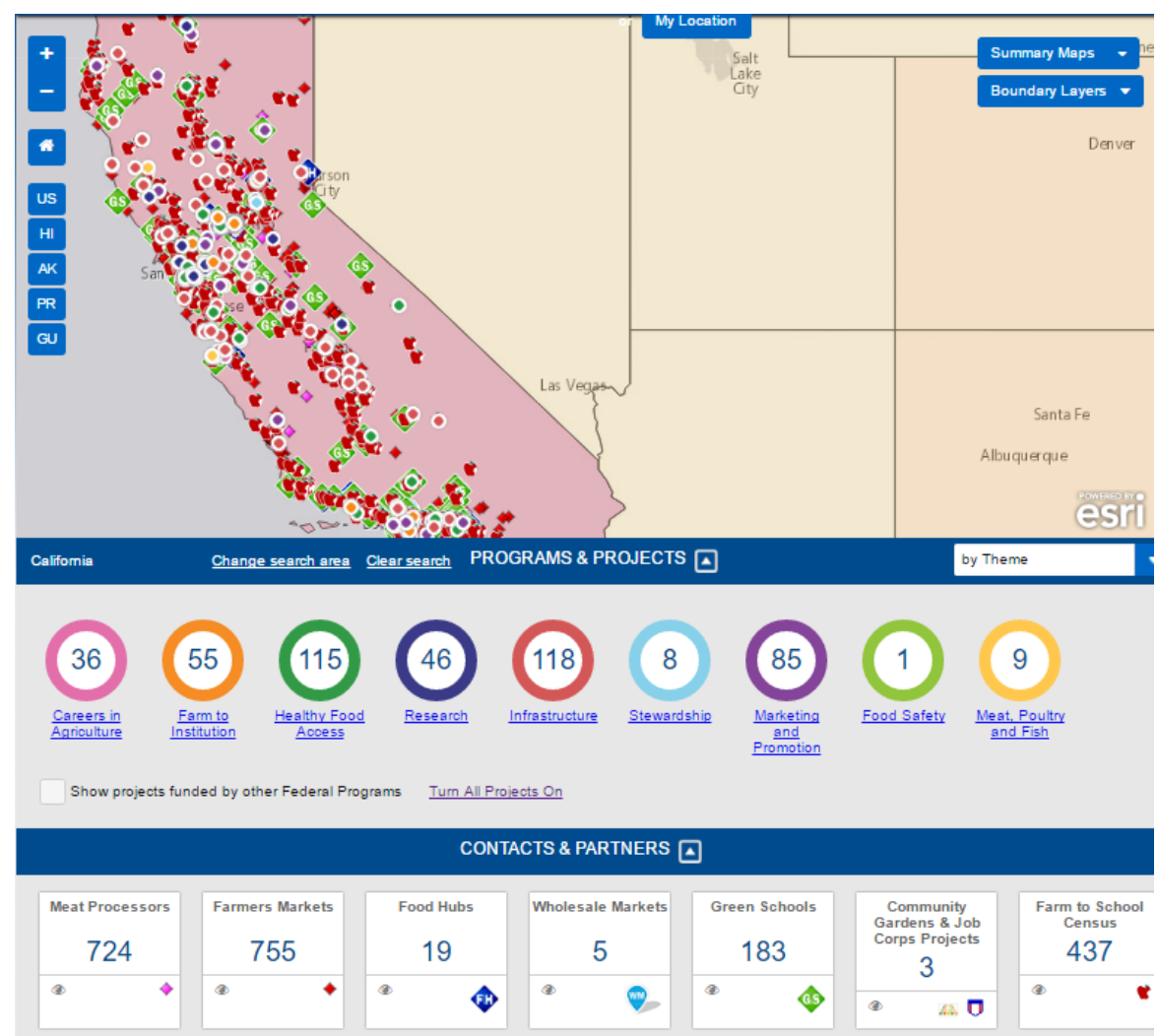

Figure 2-3: KYF Compass Map Displaying USDA Programs Related to Local Food Systems in California [url:https://www.usda.gov/wps/ portal/usda/usdamedia? navid=kyf-compass-map]. 
The creation of the KYF Compass and Map have also proved to be vital in linking consumers with producers and supporting the expansion of local food systems. The USDA believes that these tools have helped to open new markets for farmers, informed consumers on the origin of their food, and expanded local economies through buying locally produced food. Martinez et al. (2010) suggested that local food systems' popularity owes to consumer preferences based on the belief that locally produced foods are of high quality, fresher, and offer better nutritional value. Consumers also believe that local agricultural methods are environmentally friendly, an incentive to pay even more.

The Maryland food system map developed to map food and agricultural resources in the state is another good example of the application of Web GIS in improving food accessibility (Johns Hopkins Centre for a Livable Future, 2017). The web map also includes a functionality to allow researchers to download the data to conduct independent analysis. Among the mapped resources include food retail stores, food deserts and layers showing the health issues related to poor feeding like obesity and diabetes. The application helps users to locate sources of healthy foods in their neighborhoods, especially new residents who have little or no geographical understanding of the area.

\subsection{Summary}

Food accessibility is a broad problem encompassing facets including proximity to a healthy food source, local production capacity, socio-economic status of consumers, and geospatial distribution of food suppliers. Areas characterized by low food access are generally impoverished and lack food resources within a given administrative unit. GIS technology has been instrumental in strengthening local food productivity, accessibility, and the elimination of food deserts by linking them to appropriate authorities for redress. 
Finally, the chapter examines the concept of Web GIS as a cost-effective Software as a Service (SaaS) platform used by organizations to link consumers, food producers and policy makers to address food accessibility issues. This involves leveraging the analytical and visualization capabilities of GIS coupled with the advantages of using the Internet to communicate to communities. 


\section{Chapter 3 - Systems Analysis and Design}

This chapter details the project requirements, system components and project plan report. Section 3.1 discusses the problem statement. Section 3.2 tabulates and explains the functional and non-functional requirements. Section 3.3 outlines the project system design by elaborating the main project components and how they address the problem statement in section 3.1. Section 3.4 reports the project plan and execution which include tasks undertaken and resources involved during the project cycle.

\subsection{Problem Statement}

With the advent of myriad lifestyle diseases, enhancing the accessibility of fresh food has become a key goal for policy makers and administrators in the City of Riverside. The city is also increasingly interested in developing a strong local food system that not only meets the nutritional needs of its population, but also supports the local economy and contributes to decreased carbon emissions from fossil fuel consumption during food transportation (Galzki, Mulla, \& Peters, 2014). A viable local food system also tends to favor poor city residents, as small local stores located within short distances from the farm offer low prices compared to bigger stores located further away from the production areas. Consumers are also interested in knowing where their food comes from, and the methods used during farming. They are willing to pay more to local producers who use environmentally friendly methods of agriculture (USDA, 2009).

There is substantial interest by the city administration, food producers, and consumers that has led to an intriguing conversation around strengthening the local food system. Food deserts remain a bottleneck, making fresh food readily accessible, 
especially to low-income earners. Therefore, an effective method to identify and inform relevant food stakeholders about the existence of food deserts is crucial.

\subsection{Requirements Analysis}

To meet the client's needs, it was critical to work with the client to clearly define project requirements. These were then categorized into functional and non-functional requirements. Functional requirements for this project were specific details about what the web application would be able to accomplish upon user deliberate interaction. Functional requirements are initiated through user actions, e.g. clicking, panning, zoom in or out, etc. Table 1.1 is a summary of all the functional requirements.

Table 1. Functional Requirements.

\begin{tabular}{|l|l|}
\hline Requirement & Description \\
\hline Accordion & $\begin{array}{l}\text { Four expandable accordions that open one at a time were used to } \\
\text { categorize food stores and analysis layers to enable users to } \\
\text { navigate intuitively. }\end{array}$ \\
\hline Search widget & $\begin{array}{l}\text { The search widget was configured to enable search capability for } \\
\text { locations on the Esri basemaps. To facilitate this capability, the Esri } \\
\text { world geocoder was enabled. }\end{array}$ \\
\hline $\begin{array}{l}\text { Base map } \\
\text { toggle }\end{array}$ & $\begin{array}{l}\text { Esri-owned street and imagery base maps were enabled on the } \\
\text { application to give context to the vector data being visualized. }\end{array}$ \\
\hline
\end{tabular}




\begin{tabular}{|l|l|}
\hline Requirement & Description \\
\hline Home and zoom buttons & $\begin{array}{l}\text { These are standard map tools that facilitate intuitive } \\
\text { navigation of the web application. }\end{array}$ \\
\hline Layer toggle & $\begin{array}{l}\text { A checkbox for each layer was included to enable the user } \\
\text { to turn layers on and off to display on the map. }\end{array}$ \\
\hline Map legend & $\begin{array}{l}\text { A legend for each layer was displayed under the layer name } \\
\text { in the accordion menu to enable the user to differentiate } \\
\text { between various symbols on the map. }\end{array}$ \\
\hline Pop-up window & $\begin{array}{l}\text { This information window was configured on each layer to } \\
\text { display more details about features on the map. }\end{array}$ \\
\hline Layer information dialog & $\begin{array}{l}\text { A user can find more information about what each layer } \\
\text { represents by clicking on a button around the layer name. A } \\
\text { dialog appears at the top-mid section of the application with } \\
\text { informative layer details, e.g. store capacity, } \\
\text { disambiguation information, interpretation of analysis } \\
\text { results, etc. }\end{array}$ \\
\hline
\end{tabular}

Non-functional requirements describe attributes or qualitative characteristics of the web application. They support the functional requirements and functionalities. Table 3.2 is a summary of non-functional requirements. 
Table 2. Non-functional Requirements.

\begin{tabular}{|l|l|}
\hline Requirement & Description \\
\hline ArcGIS Online (AGOL) & $\begin{array}{l}\text { All the feature services were published to AGOL. The } \\
\text { application can access these data through the ArcGIS } \\
\text { Representational State Transfer (REST) endpoints. }\end{array}$ \\
\hline $\begin{array}{l}\text { ArcGIS API for } \\
\text { JavaScript }\end{array}$ & $\begin{array}{l}\text { The web application was developed using Esri's designed } \\
\text { and maintained Application Programming Interface for } \\
\text { JavaScript versions 3.19 and 3.20. }\end{array}$ \\
\hline Instinctive user interface & $\begin{array}{l}\text { The web application was developed to be easy to use and } \\
\text { intuitive enough to allow non-GIS users to produce maps. } \\
\text { This capability was enhanced by including graphics on the } \\
\text { product that are easily identifiable and relatable to the } \\
\text { features displayed on the map. }\end{array}$ \\
\hline ArcGIS Desktop 10.4.1 & $\begin{array}{l}\text { The software used to author and publish all the maps } \\
\text { consumed by the application. }\end{array}$ \\
\hline Web browsers & $\begin{array}{l}\text { JavaScript was used to develop the application to be } \\
\text { operational across common web browsers such as Chrome, } \\
\text { Internet Explorer, Mozilla Firefox, and Safari. }\end{array}$ \\
\hline
\end{tabular}

\subsection{System Design}

A system design was determined and developed based on the clients' requirements outlined in section 3.2. The system was composed of the following constituents; file geodatabase, maps, feature services and web application. Figure 3.1 shows the system design. 


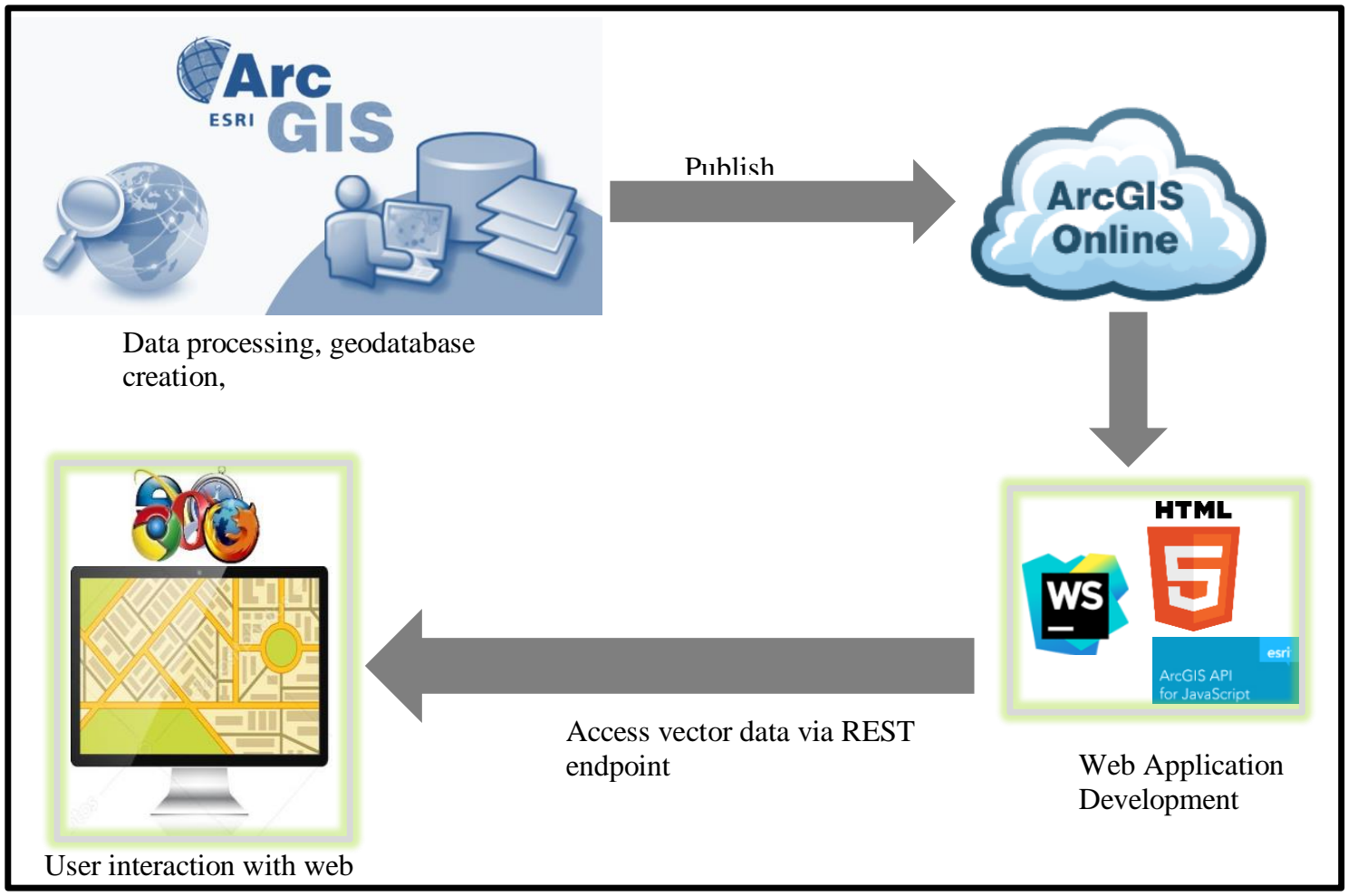

Figure 3-1: System Design.

\subsubsection{File Geodatabase}

A file geodatabase was designed using ArcCatalog 10.4.1 tools to hold all the datasets required to author maps, conduct spatial analysis, and publish feature services to ArcGIS online to be consumed on the web mapping application. ArcGIS File Geodatabase is an Esri invented and managed product that offers unlimited storage space and features that support data integrity such as subtypes, domains, and topology.

\subsubsection{Feature Services}

Five map documents were authored in the ArcGIS 10.4.1 environment. One of the map documents visualized healthy food access analysis results while the other represented food stores as point features in the City of Riverside. All the maps were published to the Redlands ArcGIS Online server during development and later transferred 
to the City's server during system deployment. The hosted feature services REST URLs were used to call and display the vector data on the web application front-end.

\subsubsection{Web Application}

Figure 3.2 shows the front-end interface of the web application. The application's main role was to visualize food stores data and food accessibility results. Data displayed on the application was accessed from ArcGIS server using REST URLs of the feature services discussed in section 3.3.2. When the application is initiated on a web browser, farmers' markets and supermarket features are displayed. The user can intuitively navigate through using various options such as turning layers on and off, changing basemaps, querying vector data or finding layer information by clicking on a layer button.

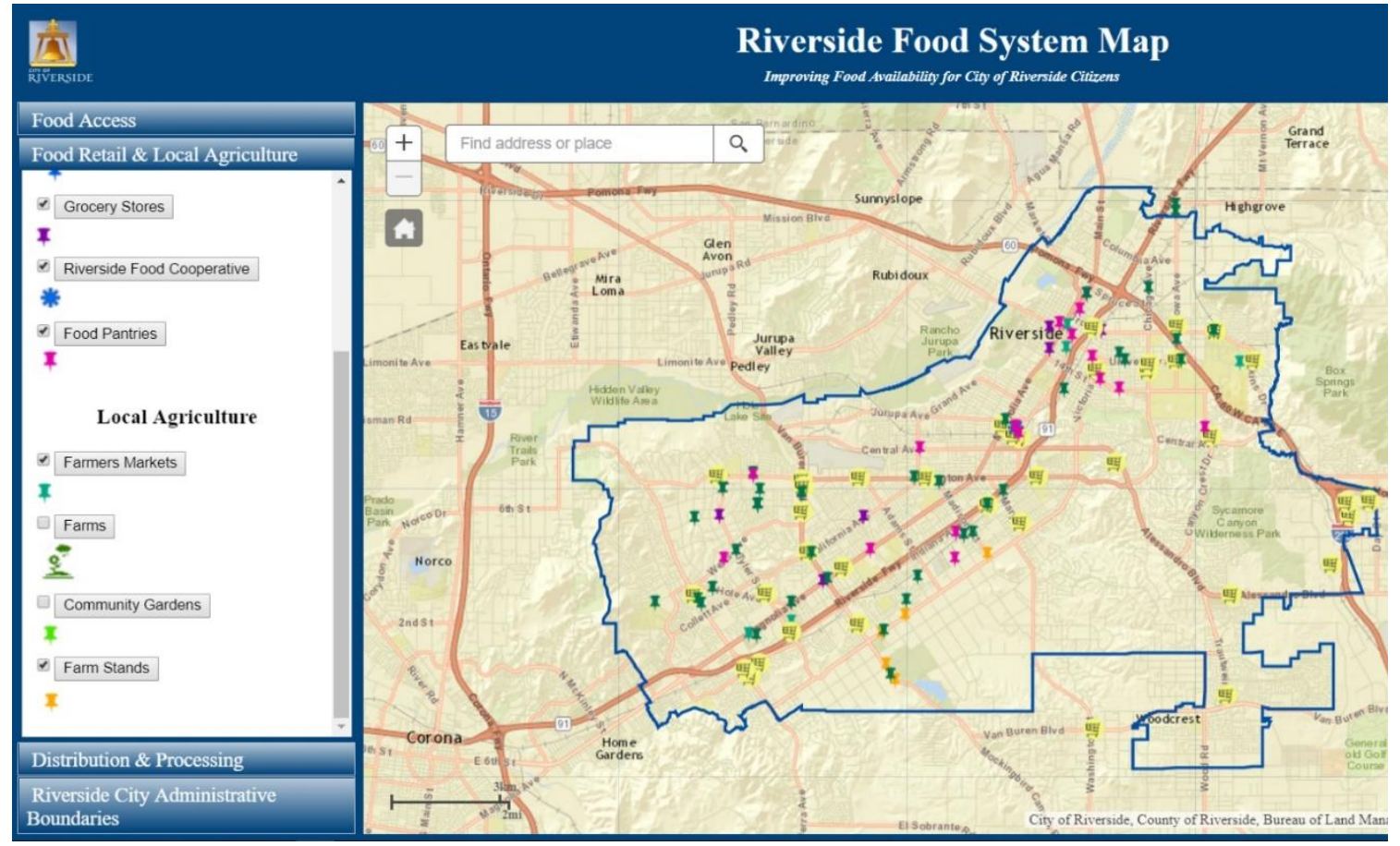

Figure 3-2: Web Application Interface. 


\subsection{Project Plan}

The project plan comprised the following phases: planning, project design, development, and deployment. During the planning phase, various tasks were completed. The project scope and study area were settled upon through studying existing products including the Maryland Food Systems Map (Johns Hopkins Centre for a Livable Future, 2017). This phase had challenges pertaining to the clarity of project goals and objectives. The planning phase of the project occurred from September to December 2016. The first

prototype web application was developed using Web App Builder template as a proof of concept and delivered in January 2017 to the client. This was deemed insufficient due to the amount of customization required to develop the envisioned web application. The ArcGIS for JavaScript API was preferred for application development due to its flexibility.

The next phase involved defining system requirements and major components of the project. This also involved the acquisition of relevant data from the client and other sources described in chapter four. These data were processed and stored in a temporary file geodatabase. These activities were completed in February 2017.

The development phase which involved the creation of the final file geodatabase, map documents, and web application began in March 2017. On March 30, 2017, the second prototype of the web application as well as preliminary food access analysis results were delivered to the client at the $4^{\text {th }}$ Annual GrowRIVERSIDE Conference held at the La Sierra University in Riverside, California. Subsequent updates were relayed to the client every two weeks. Quality control and testing were conducted at regular meetings with client feedback and recommendations incorporated as necessary during 
development. More data were also provided at this phase to complement the initial batch. An analysis to identify areas within the city whose residents have low food access was also conducted during this phase. In this analysis, socio-economic factors and distance to a store were identified as the main impediments to healthy food accessibility.

The project was completed in August 2017. The project final deliverables provided to the client involved transfer of feature services to the client's ArcGIS Online account, map documents, and training on how to update layers on the application. The web application source code and user specification manual were also delivered to the client.

\subsection{Summary}

This chapter outlined the project initiation, planning, development, and deployment activities undertaken during the project lifecycle. Functional and non-functional requirements were discussed in this chapter. The system design, including major components and deliverables, was also discussed. The major tasks undertaken during the project cycle were introduced. This chapter lays the foundation for Chapters Four and Five, which explain the database design and implementation respectively. 


\section{Chapter 4 - Database Design}

The data used in this project were selected to support the implementation of the requirements discussed in Chapter 3. Both the web development and the food accessibility analyses were based on depicting the distribution of food from the markets and producers to the consumers. Section 4.1 discusses the conceptual data model design which explains the main components of the project design and their relationships. Section 4.2 outlines the logical data model design as the physical representation of the database structure including feature classes and their attributes. All the data sources for this project are discussed in Section 4.3. Methods used to scrub, clean, and load data onto the file geodatabase are introduced in Section 4.4. The chapter ends with a summary of each of the sections mentioned above.

\subsection{Conceptual Data Model}

The conceptual model is a broad representation of the main components of this project database and how they relate with each other. This is summarized in three broad categories: food sources, consumers, street network, food processors, food deserts and the. All the data used for this project fall in one of these three main categories. Figure 4.1 shows the project conceptual model. 


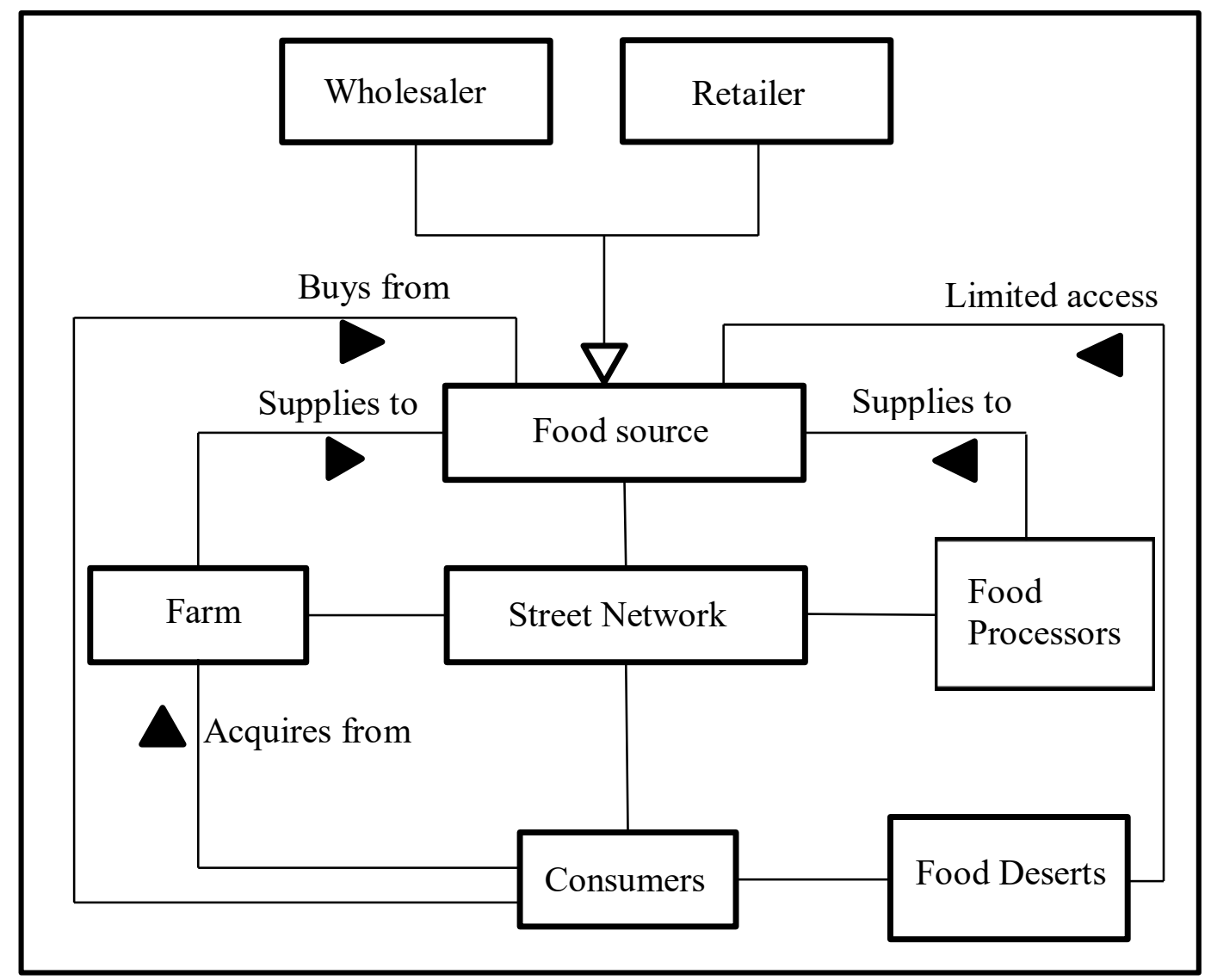

Figure 4-1: $\quad$ Conceptual Model.

Food sources include both retail and wholesale outlets that are involved in the distribution of food to the final consumer. Consumers are people who acquire this food with an aim of eating it. In this model, a farm is an entity that is involved in growing or producing foods naturally. These foods include plant- and animal-based products. Food sources are various supply points that consumers can walk in to buy food. The street network connects the consumers with food distributors. The street network was used to model how people get to food sources. There are various ways in which consumers get to food sources including walking, driving or by means of public transport. Consumers living in food deserts face various hurdles that hinder them from accessing food from various distribution points. 


\subsection{Logical Data Model}

The logical data model is a physical representation of the database structure including feature classes and their attributes. It is a derivation of the conceptual data model showing data and how they relate within the database. Figure 4.2 illustrates the logical data model.

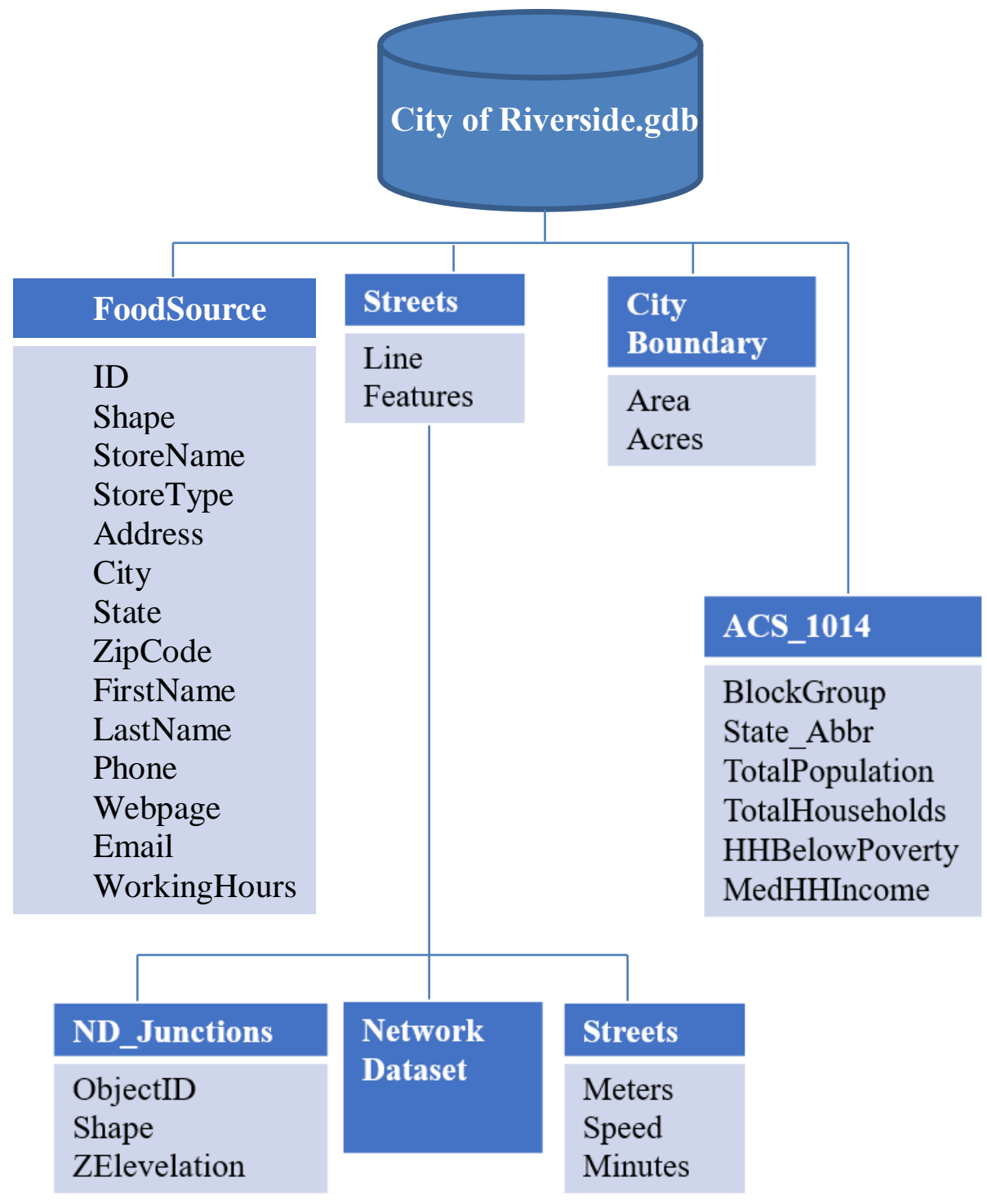

Figure 4-2: $\quad$ Logical Model. 
Data for this project were stored in an Esri file geodatabase designed using ArcCatalog 10.4.1. The database was comprised of four feature classes: food sources, streets, city boundary, and Esri American Community Survey (ACS) data. The food sources feature class had 199 features and 14 attributes describing each outlet. The streets feature class was used to create a network dataset which was used in the food accessibility and desert analysis. The network dataset created included junctions point feature class and edges connecting them to model movement along the streets. The network dataset was modeled to factor in real world navigation along the streets, such as one-way, speed limits, walking, and drive times. Streets are considered as the main routes that consumers use to get to the food sources. Both the network dataset and streets feature classes were stored in a feature dataset within the file geodatabase. The city boundary feature class was also stored in the geodatabase to provide context for the data and to define the study area of the project. ACS_1014 feature class involved all 217 census block groups in the City of Riverside. Other attributes in the ACS_1014 feature class include: population count, median income, and poverty data.

\subsection{Data Sources}

The main data sources for this project were the City of Riverside, 2010-2014 Esri American Community Survey (ACS) Estimates, and 2014/2019 Esri US Demographic Updates. The 2014/2019 Esri US Demographic data provided income data for 2014 to complement ACS estimates for the same period. The 2009 Esri Streets data, 2010-2014 Esri American Community Survey (ACS) Estimates, and 2014/2019 Esri US Demographic data were acquired from the University of Redland's Center for Spatial 
Studies. The client provided the rest of the data, including the food sources and city boundary. Table 4-1 is a summary of all the data sources used in this project.

Table 3. Data Sources.

\begin{tabular}{|l|l|l|l|}
\hline Dataset & Source & Date & Purpose \\
\hline Food sources & City of Riverside & 2017 & $\begin{array}{l}\text { Analysis and } \\
\text { visualization on the web } \\
\text { application }\end{array}$ \\
\hline Streets & Esri & 2009 & Analysis \\
\hline ACS_1014 & $\begin{array}{l}\text { Esri American Community } \\
\text { Survey and 2014/2019 Esri } \\
\text { US Demographic Updates }\end{array}$ & $2010-14$ & Analysis \\
\hline City Boundary & City of Riverside & 2017 & $\begin{array}{l}\text { Analysis and } \\
\text { visualization on the web } \\
\text { application }\end{array}$ \\
\hline
\end{tabular}

\subsection{Data Scrubbing and Loading}

Both the city boundary and neighborhoods data were received and loaded onto the file geodatabase without any changes. Food sources data were received in Excel Workbook format before conversion to CSV format. The features in these data were then geocoded in ArcMap using the World Geocoding Service which is an ArcGIS Online service. Geocoding was conducted using address attributes in the data, including street address, ZIP code, and city. The geocoded features were then transferred into the food source feature class stored in the file geodatabase. Some of the food sources data were received in a shapefile and loaded to the food sources feature class using the Simple Loader tool in ArcMap. 
The ACS_1014 feature class was created in ArcMap with the fields to contain data required for the project analysis. Before loading ACS and CFY data into the feature class, the block groups that lie within the City of Riverside boundary were selected. The target fields in these block groups were then loaded onto the feature class designed in the file geodatabase. This feature class was then used to clip the street data using the Clip tool. The streets data were then used to model the network dataset using Network Analyst. Both walking and drive times were modeled in the dataset using the minutes, speed, meters, elevation, and one-way attributes in the street feature class. The streets and the resulting network dataset were then loaded onto feature dataset within the file geodatabase.

\subsection{Summary}

This chapter outlined the data requirements and design for this project. The conceptual data design model, a representation of the main components of the project and their relationships, was discussed. This was followed by the outline of the logical data design model, which gives structural details of the file geodatabase including feature classes, their attribute fields, and the relationships therein. The data sources for this project were also discussed, followed by methods used to scrub and load them into the geodatabase. The methods used to obtain and prepare data in this chapter were critical to determine the accuracy of the analysis results of the project. 


\section{Chapter 5 - Implementation}

The focus of this project was to create an online organized repository of the City of Riverside food resources to upgrade an existing static map on its website. This task was accompanied by conducting an analysis using spatial data to determine the existence of food deserts. Some of the analysis results maps were then uploaded to ArcGIS Online and displayed on the web application for users to explore by querying or overlaying them with other layers to establish any existing patterns. Section 5.1 of this chapter describes the process undertaken to identify food deserts. Section 5.2 and 5.3 then outlines how the maps for the project were created and their publication as feature services to ArcGIS

Online respectively. Section 5.4 introduces the web application development process before a summary of the entire chapter is provided in section 5.5.

\subsection{Spatial Analysis to Identify Food Deserts}

As described in chapter two, food deserts are poor neighborhoods lacking healthy food sources. Therefore, food deserts are closely linked with demographic attributes and availability of sources that provide healthy versus fast foods (Herries, 2010). As much as accessibility plays a crucial role in healthy feeding, Herries noted that individuals have the liberty to choose what they eat. To define the scope of this project, it was decided in consultation with the client that distribution of sources believed to stock healthy food and affordability as determined by income levels would form the spine of this analysis.

Accessibility can be determined by either distance or time taken to reach a food source. The USDA definition of food deserts in urban areas has benchmarked this distance to be one mile. In other cities such as Baltimore, Maryland, through public 
interviews, researchers determined that residents were only willing to walk 0.25 mile to a food store (Johns Hopkins Centre for a Livable Future, 2017). The study of food deserts is hindered by lack of a standard threshold distance (Jiao et al, 2012). However, as discussed in chapter two, a 500-metre radius was the common threshold used by researchers in the 1990s as the topic of food deserts continued to gain momentum (Hallet IV \& McDermott, 2010). In modern urban development, neighborhood designers try to ensure that most crucial facilities including food sources should be located within $500 \mathrm{~m}$ radius (Huang \& Pike (2016). Upon discussion with the client, 500-meter distance from a healthy food source was agreed on as the limit to accessibility to a food source.

The food sources considered for this analysis were discussed and agreed upon with the City of Riverside staff in the Economic and Community Development Department. Their decision was based on their understanding of these sources from their work experience in the office and interaction with consumers and food sources owners in the city. The City of Riverside considered the following stores as crucial healthy food sources for its residents: supermarkets, grocery stores, corner stores, farmers markets, food pantries, and farm stands. Supermarkets such as Stater Brothers, Albertsons, and Ralphs were included in the analysis due to their large capacity to stock various types of fresh foods in large quantities. Corner and grocery stores are smaller in size than supermarkets but stock a variety of fresh and healthy foods. Some of the corner stores considered for this analysis were Ranch Market, Garcia's Produce, etc. while grocery stores included the Maxi Foods, Lucky 1 Food Store, etc. Foods sold at farmers markets are mainly produced locally. Farmers markets offer both competitive prices to consumers and fresh produce. For example, some of the farmers markets such as the Riverside 
Downtown and Kaiser Permanente open once every week to the public to purchase locally produced foods. Finally, food pantries which mainly distribute food to poor residents who cannot afford to purchase food from conventional sources. Examples of food pantries in the City of Riverside include Feeding America, The Concerned Family, etc.

ArcGIS 10.4.1 Network Analyst extension was used to model navigation along the street network. This method represents a more realistic and accurate model of mobility compared to ring buffers that assume that one moves in a straight line from point A to point B (Kuai \& Zhao, 2017). All restrictions such as 'One-ways' and 'Noturns' were not included because humans were assumed to prefer using sidewalks to walk to food sources. The healthy food sources were then added to the network analyst layer using the Add Locations tool in ArcMap as destinations for consumers. 500-metre service areas around these sources were then created. Figure 5.1 shows areas within the City of Riverside that are within 500 meters of healthy food sources. 


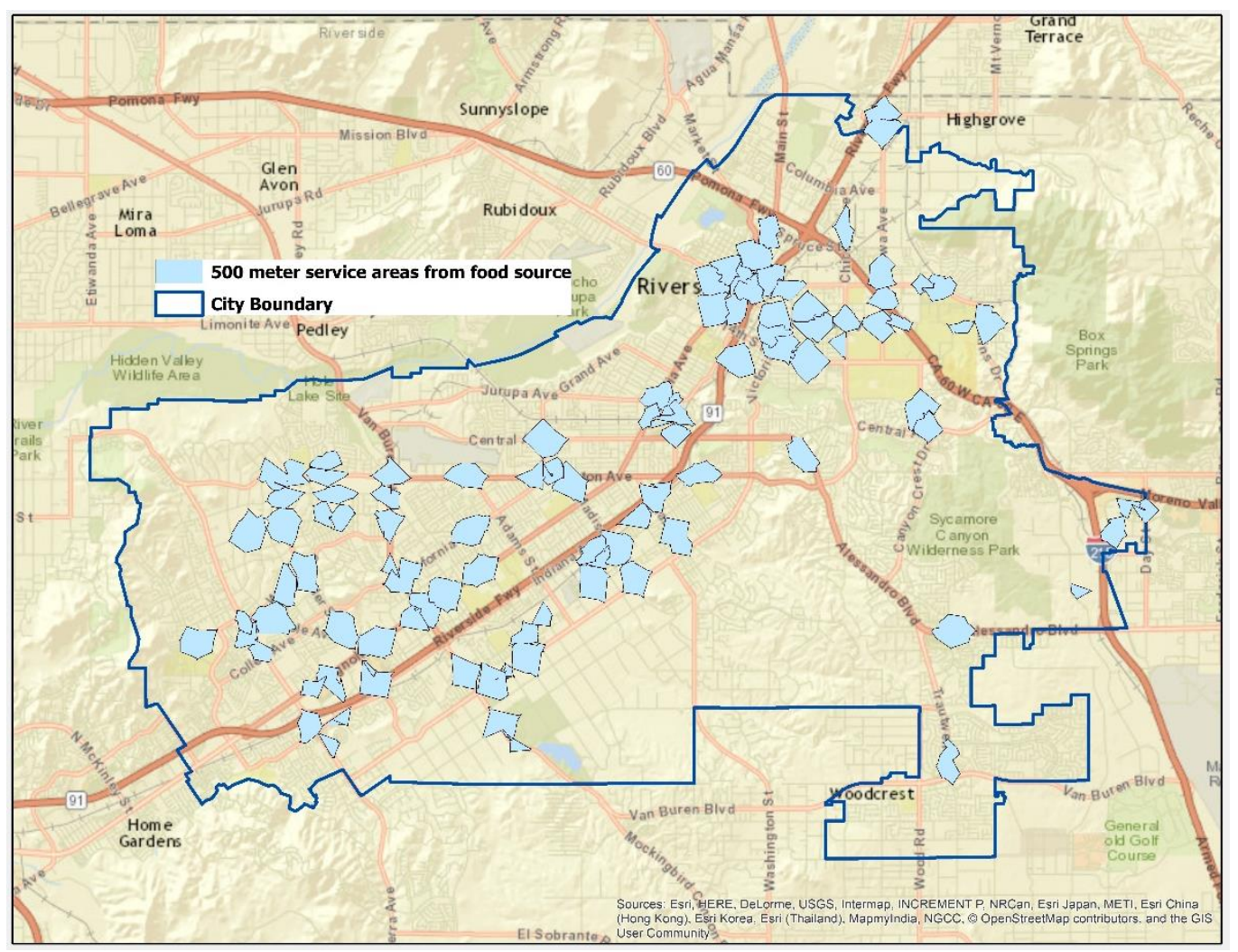

Figure 5-1: $\quad$ Areas Serviced by Healthy Food Sources within 500M Distance.

Census block groups were then overlaid to determine the portion of population with access to food stores. This process was achieved under the assumption that population at census block group level is evenly distributed (see chapter six). Therefore, the percentage of serviced area per block group would represent the total population that has access to healthy food.

The Tabulate Intersection tool in ArcMap was used to determine the percentage population with access to food sources in each block group. The results were an output table showing the intersecting percentage of serviced areas in each block group as illustrated in Figure 5.2 below. While generating service area polygons using the Network Analyst Service Area tool, the Not Overlapping and Disks properties were 
selected under the Layer Properties section. This enabled each polygon intersection with the overlaid block group polygons to be accounted for only once in the analysis as shown in Figure 5.3.

\begin{tabular}{l} 
Sumstats \\
\begin{tabular}{|r|r|l|r|}
\hline \hline & OBJECTID * & Block Group & SUM_PERCENTAGE \\
\hline 2 & 2 & 060650301031 & 49.7 \\
\hline 3 & 060650301032 & 36.2 \\
\hline 4 & 060650302001 & 1.8 \\
\hline 5 & 060650302003 & 48.1 \\
\hline & 6 & 060650302004 & 1 \\
\hline 7 & 060650302005 & 16.4 \\
\hline & 8 & 060650303001 & 91.9 \\
\hline 9 & 060650303002 & 35.2 \\
\hline 10 & 060650303003 & 48.7 \\
\hline 11 & 060650303004 & 96.7 \\
\hline 12 & 060650303005 & 73.6 \\
\hline 13 & 060650304001 & 75.7 \\
\hline 14 & 060650304002 & 15.3 \\
\hline 15 & 060650304003 & 43.5 \\
\hline 16 & 060650304004 & 40.4 \\
\hline 17 & 060650304005 & 65.4 \\
\hline 18 & 060650305011 & 10.2 \\
\hline 19 & 060650305012 & 78.1
\end{tabular} \\
\hline-
\end{tabular}

Figure 5-2: Areas Serviced by Healthy Food Sources within 500M Distance. 


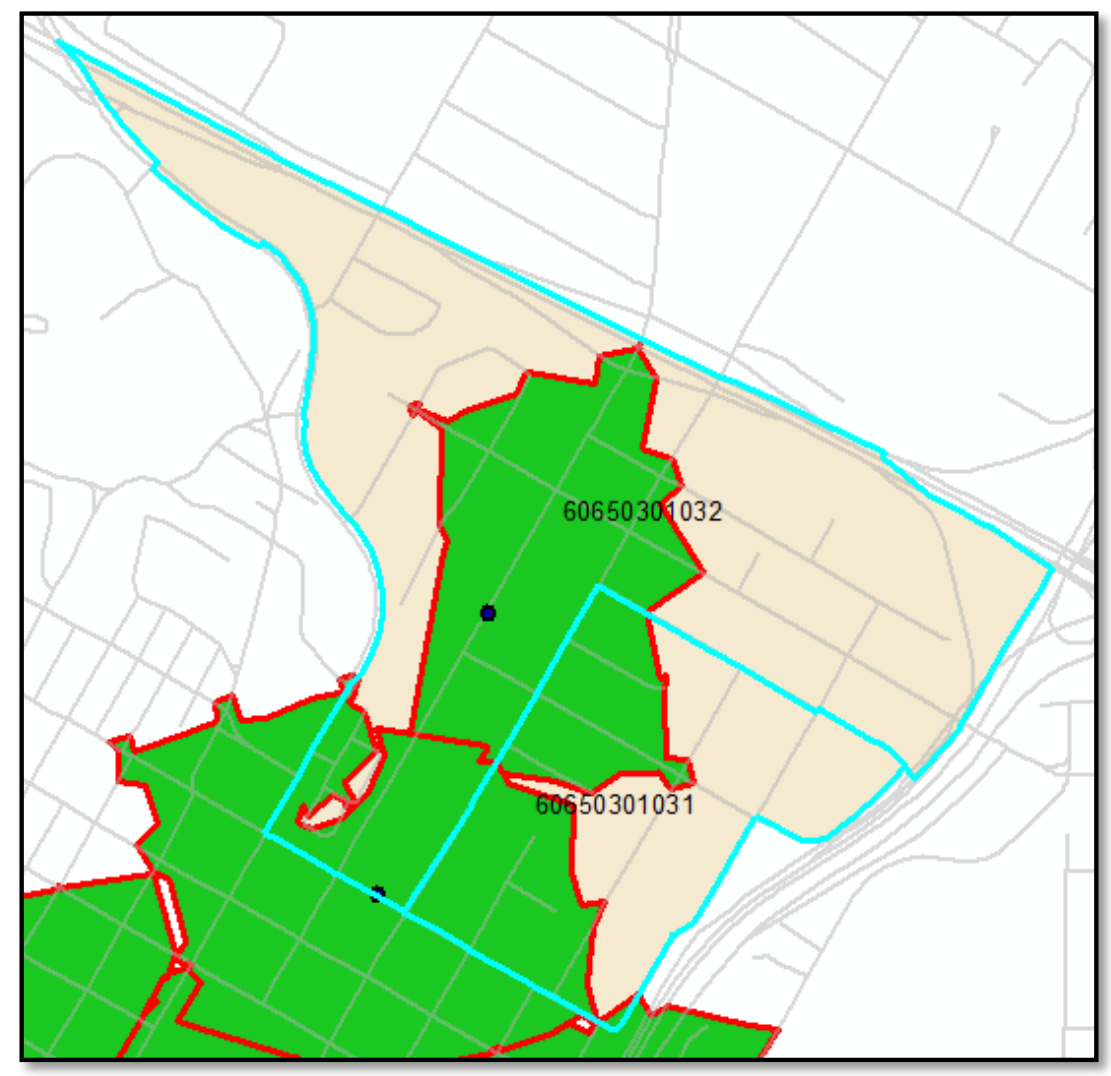

Figure 5-3: Logical Block Group 06065031031 and 6065031032 Population with Access to Healthy Food Source is $49.7 \%$ and $36.2 \%$ Respectively.

In its definition of food deserts, the USDA states that at least $33 \%$ of the population in a census tract must live one mile outside the reach of a healthy food source (USDA, 2011). This definition does not include a criterion for block group level. In consultation with the City of Riverside, it was decided that if $33 \%$ of the population in a block group live outside 500-metre distance from a healthy food source, it would be considered as having limited food access. The Selection by Attributes tool was used to isolate block groups where $33 \%$ of the population or more live outside a 500-meter radius from a healthy food source. These were identified as block groups with limited food access.

To complete the identification of food deserts, median household income data at block group level were then introduced in the analysis. First, the dataset containing the 
median household income attribute was joined to the 217 block groups in the city using the Spatial Join tool in ArcMap. Second, a definition query was developed based on the following criteria:

- $33 \%$ of the population in a census block group live outside a 500-meter distance from a healthy food source

- Block groups with a median household income of $\$ 43,000$ or less. This Figure represents approximately $80 \%$ of the city's median household income which was $\$ 54,444$ in 2016 according to Applied Geographic Solutions. USDA (2011) uses a similar method to identify tracts that have low access to healthy food.

The definition query developed was as follows; Definition Query = $(($ NOFoodPercent $=>33$ AND MEDHHINC < = 43000) AND $($ MEDHHINC >0)), where NOFoodPercent is the percentage population living outside one-mile distance and MEDHHINC is the median household income of block group. The results of the query were used to create a map layer representing block groups with low food access shown in Figure 5.4. The Erase Tool in ArcMap was then used to remove all the serviced areas shown in Figure 5.3 from the low-income block groups resulting to the final Riverside food deserts. The map in Figure 5.5 represents the City of Riverside food deserts.

The Riverside food deserts are impoverished areas whose residents have no access to a healthy food store within a 500-meter radius (approximately 0.3 miles). The results of this analysis are discussed further in the next chapter. 


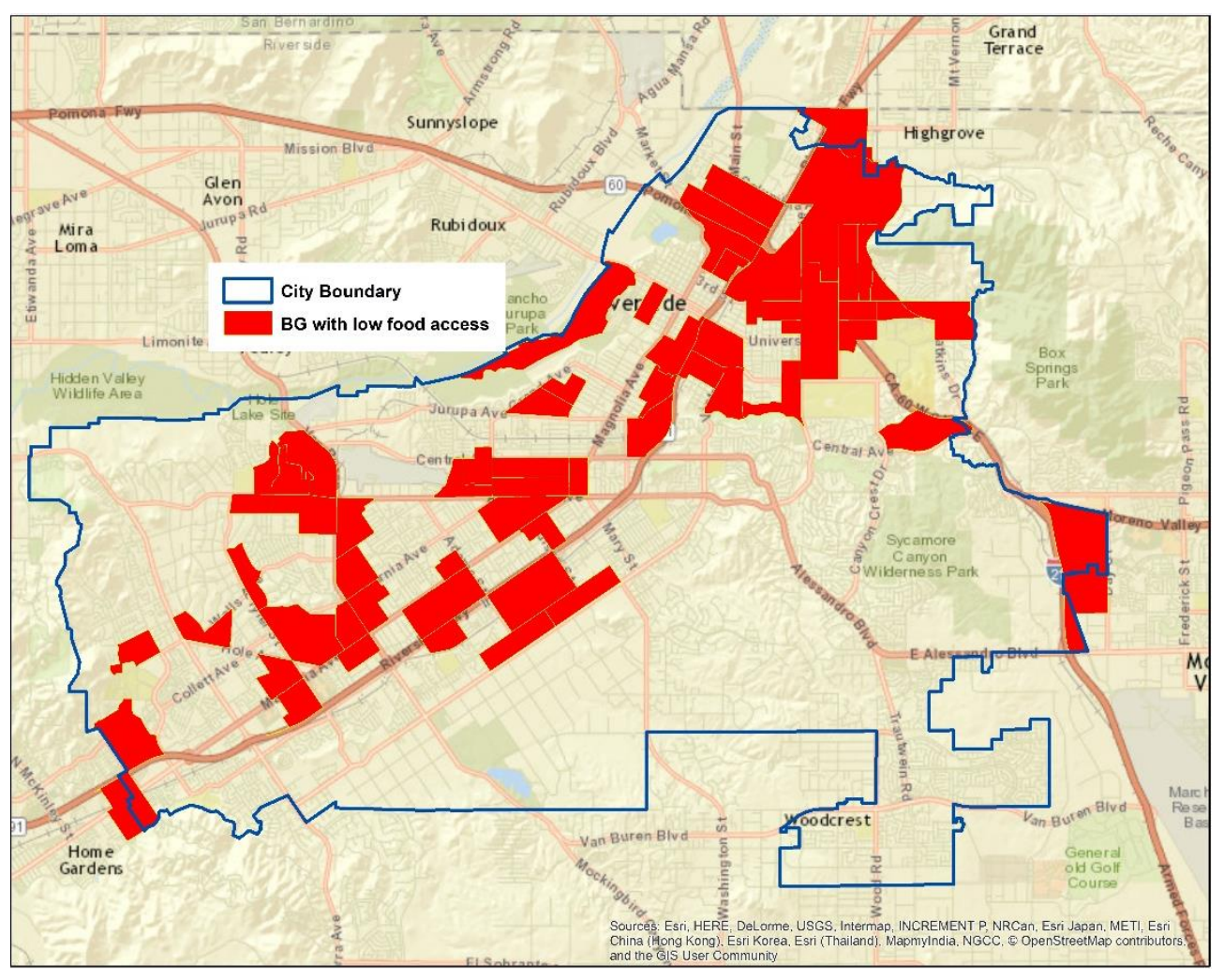

Figure 5-4: $\quad$ Block Groups with Low Food Access

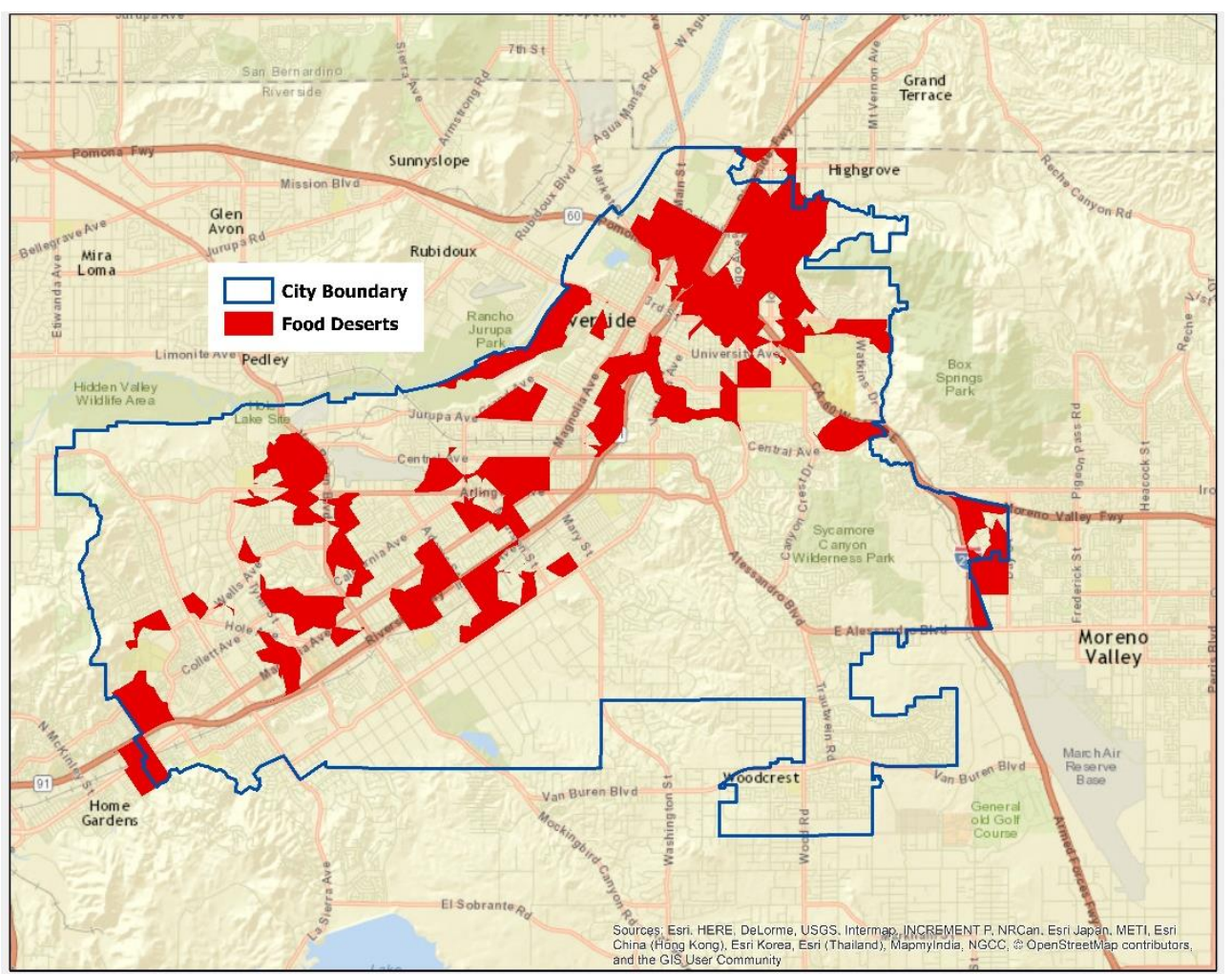

Figure 5-5: Riverside Food Deserts. 


\subsection{Preparing the Food Resources Map Document}

All the maps for the project were prepared using ArcGIS for Desktop 10.4.1. One of the objectives of this project was to create a repository of all food resources. To achieve this, a map of all food resources was created. These resources were grouped into two broad categories: wholesale and retail. Wholesale resources included food manufacturers and packaging companies that produce food in bulk. These do not sell directly to the consumer in the distribution chain. On the other hand, retail resources include commercial outlets such as farm stands, grocery stores, convenience stores, supermarkets, and corner stores. Other resources in this category include community gardens and food pantries. Food pantries receive food from food banks that collect relief food for distribution to low-income residents (Bhattarai, Duffy \& Raymond, 2006). In the City of Riverside, churches or community members operate most food pantries. Community gardens are collectively owned and operated by a section of community members whose motivation is to produce their own heathy food (Schmelzkopf, 1995). The symbols representing the various resources were simple because a large section of the target audience for the web application have limited GIS skills or may be unwilling to spend much time reading the map details (Brewer, 2016). Figure 5.6 shows a map of food resources in the City of Riverside. 


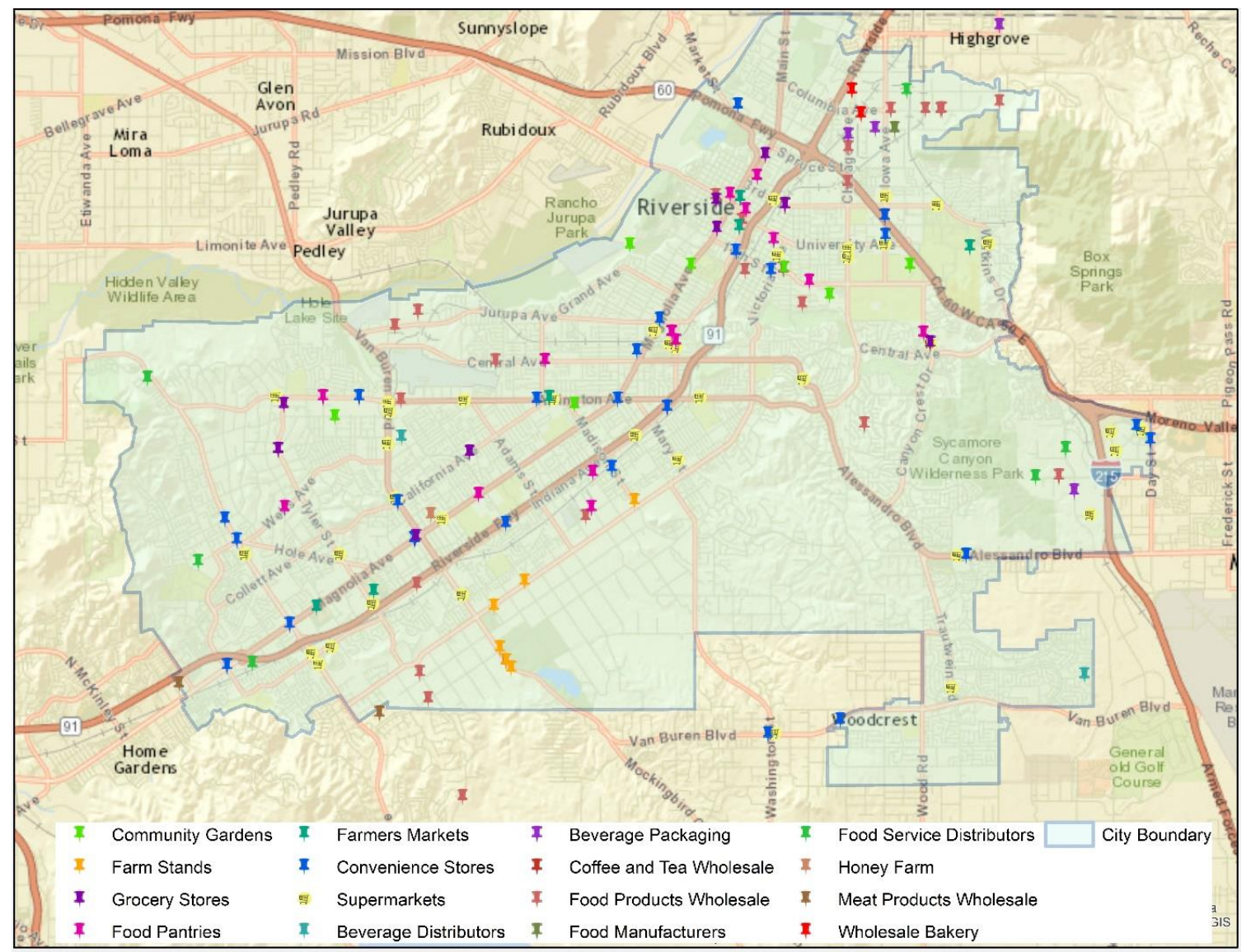

Figure 5-6: Riverside Food Sources.

\subsection{Publishing Feature Services}

Map documents that would be consumed by the web application were published to ArcGIS Online as feature services. These included the food resources map, food desert map, low-income census block group map, and the healthy food accessibility map.

Feature services provided important capabilities required for this project including the ability to display, query and update vector data on the web application (Esri, 2017). The hosted feature services could also be edited by the client in future.

Publishing feature services requires logging into an ArcGIS Online organizational account. During the development stage of the project, all the feature services were 
published to University of Redlands ArcGIS Online student account. They were then transferred to the City of Riverside ArcGIS Online account for hosting during deployment of the web application. The feature services were then published from ArcMap with the Create, Delete, Query, Sync and Update capabilities checked as shown in Figure 5.7. Enabling these capabilities allows a user to query the feature service data including non-spatial types, and allows the client to edit the data in future. The final step before publishing was to analyze and correct errors such as unsupported layers or symbols for feature services.

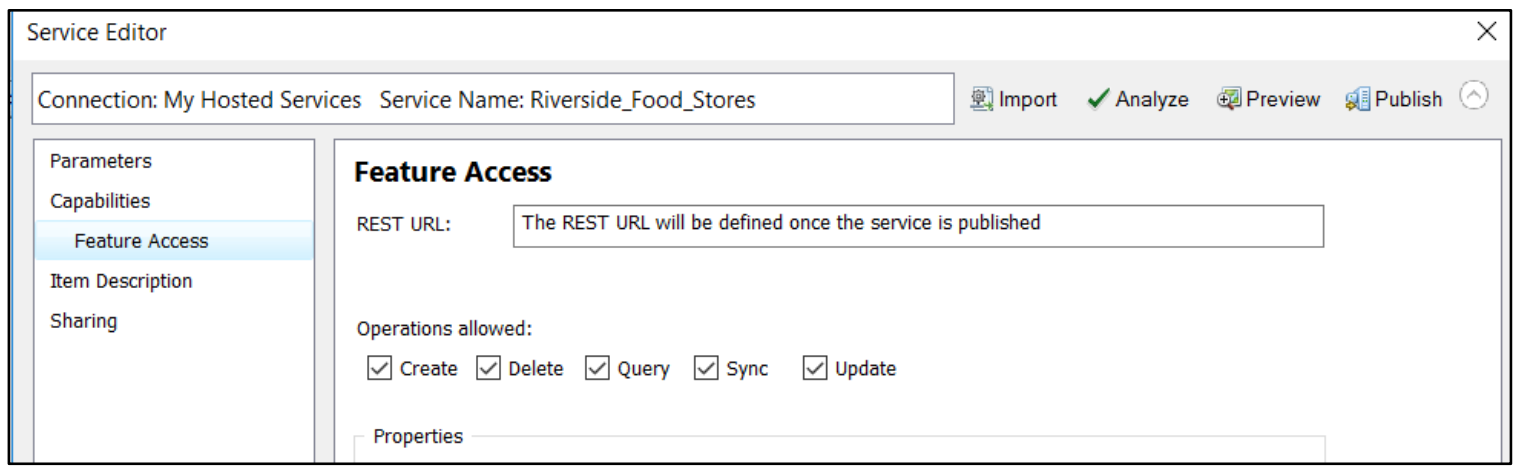

\section{Figure 5-7: The Service Editor Menu in ArcMap.}

\subsection{The Web Application Development}

The web application was built mainly using the ArcGIS API for JavaScript which is presented on top of JavaScript (Fu, 2016) and Dojo toolkit. The ArcGIS API for JavaScript provided code resources to create widgets that improve user experience while interacting with the application. The Integrated Development Environment (IDE) used to write the application source code was JetBrains WebStorm 2016.3.3. It is a JavaScript, HTML, and CSS editor that offers capabilities such as code formatting and documentation, error detection, and debugger tools for common browsers such as 
Chrome and Mozilla Firefox. The IDE has a built-in HTTP server to support visualization and interaction of the web application on the web browser during development prior to deployment to the client web servers.

To keep the code neat and organized for easy documentation and debugging, the three languages namely HTML, CSS and JavaScript were saved in separate folders. A separate folder for images and symbols used on the application interface was also created. JavaScript, the most widely used programming language, was used to develop responsive and interactive web application functionalities (Fu and Sun, 2011).

HTML5 was used to create the main elements of the application which include the title pane, accordion menu, and the map display element. Figure 5.8 shows the main front-end components of the web application. All these elements branch off as children from a parent BorderContainer dijit created using the $\langle$ div $>$ tag. When building a child dijit or widget from a parent using the < div> tag, its position on the web page must be specified using the "data-dojo-props" attribute whose options include top, bottom, right, left, center, etc.

The title pane (top) was created using the Dojo ContentPane dijit to hold the application title and the City of Riverside and growRIVERSIDE logos. The two logos are linked to their respective websites for access in a new tab when clicked. The growRIVERSIDE website belongs to an initiative by local agricultural and food stakeholders who work hand in hand with the city administration to improve food accessibility through developing a strong local food system.

The accordion menu was created using the Dojo AccordionContainer dijit while its four expandable children panes were designed using the Dojo AccordionPane dijit to display 
the list of layers on the application. The Local Agriculture and Community Gardens pan contains farmers markets, farms, community gardens and farm stand layers. The Food Retail and Access pane was used to organize the following layers; supermarkets, corner stores, convenience stores, grocery stores, food pantries, low-income layer, food deserts layer and the healthy food accessibility layer. The Distribution and Processing pane contains wholesale food resources while the Riverside City Administrative Boundaries holds the city boundary, neighborhoods, and wards layers. Under each layer name is a symbol representing respective features that display on the application map element. The user can toggle on and off layers using checkboxes against each layer. A button on the name of each layer opens a dialogue box when clicked to display descriptive information, e.g. the dialogue box for the analysis layers provides information about the analysis criteria and results for easy interpretation of the maps by users. 


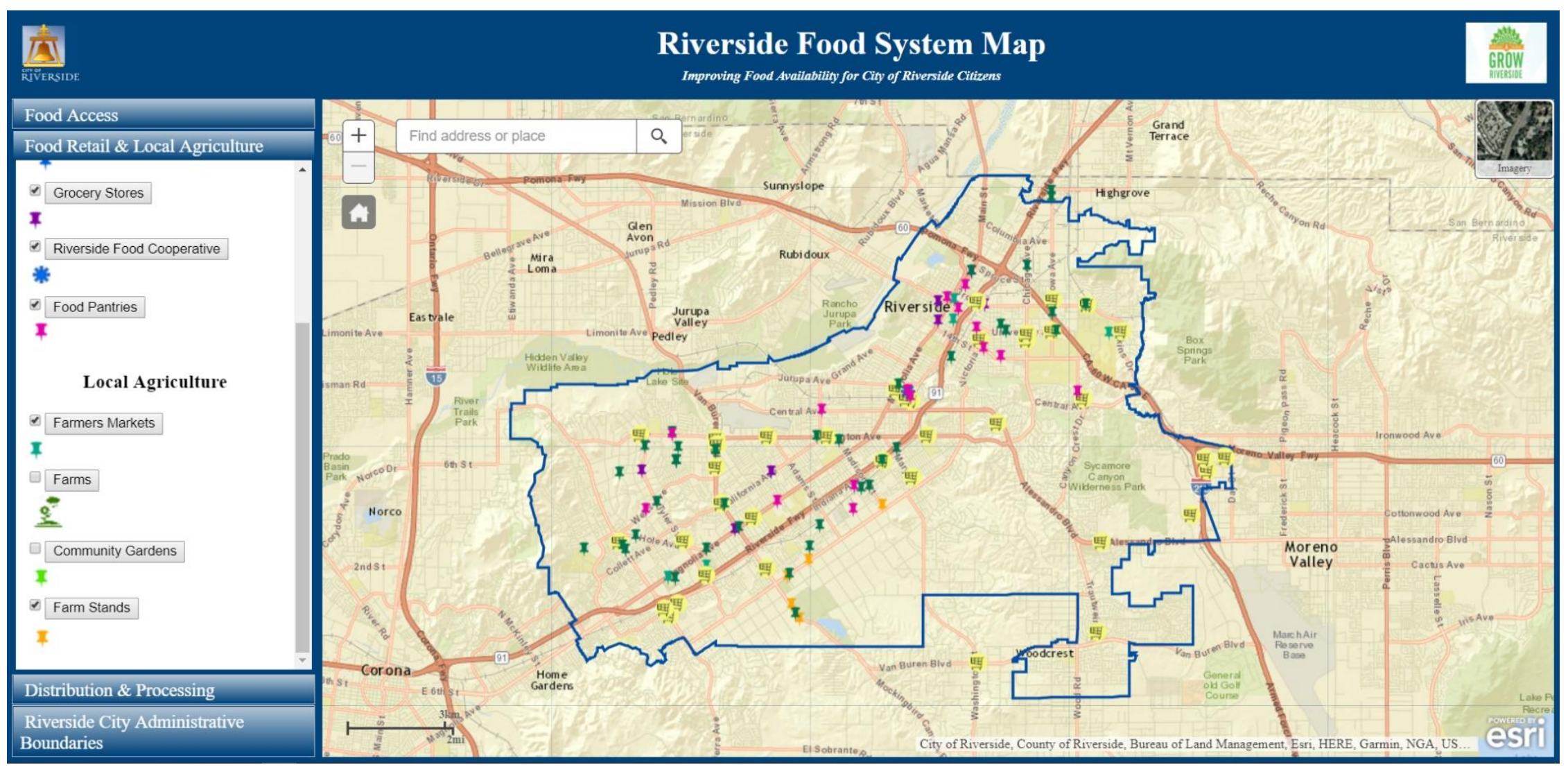

Figure 5-8: The User Interface of the Web Application. 
The display map element was developed using the Dojo ContentPane dijit. It occupies approximately $70 \%$ of the total web page to provide adequate visualization of features. This element also contains a basemap toggle widget to enable the user to change basemaps, a locator/search bar to facilitate finding addresses or locations on the map, a home button and zoom widgets for user navigation of the application and a scale bar. An information window is enabled for most of the layers to display nonspatial information about features on the map such as physical addresses, feature names, contact information, webpage links, working hours, and notes as shown in Figure 5.9. CSS3 was then used to improve the web page appeal through styling of fonts, colors, width, height, and positional properties of the various elements of the web application.

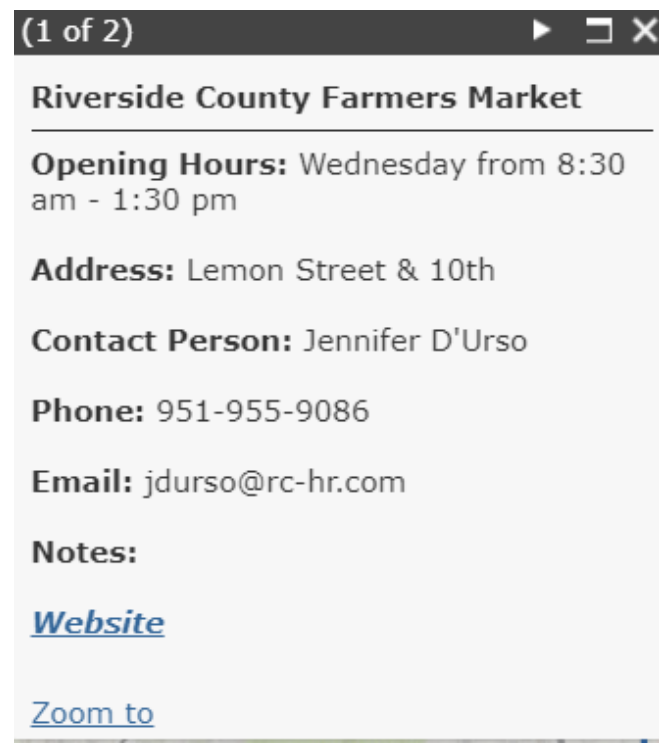

Figure 5-9: The Information Window (Pop-up) Showing Feature Attributes.

\subsection{Summary}

Chapter 5 was an outline of the steps undertaken to implement the project solution. These included an analysis using ArcGIS Desktop tools and the development of a web 
application using the ArcGIS JavaScript API as the main JavaScript library, Dojo toolkit and HTML5 to design the web page elements and CSS3 for styling element characteristics such as font, height, width, position, and color. The main parts of the web application, different widgets, and their functionalities were also discussed in this chapter. 


\section{Chapter 6 - Results and Analysis}

This chapter discusses the utility of the project deliverables which include food accessibility analysis maps and a web application. Section 6.1 introduces food desert study and analysis with a focus on the ways in which the results could be a positive trigger to attract help from relevant authorities. Section 6.2 is an outline of the web application functionalities and their importance in improving user experience. User cases are described in Section 6.3 to demonstrate different ways in which the web application can benefit various users with different needs. The chapter then ends with an analysis of limitations of the project and a short summary of the chapter in Sections 6.4 and 6.5 respectively.

\subsection{Food Deserts}

The criteria used to identify food deserts in this project was based on distance from a food source and income levels at the block group level. In the analysis, a block group was described as having low food access if $33 \%$ of its population live beyond 500 meters from a healthy food source and the median household income was equal or less than $\$ 43,000$. The criteria were discussed in detail in chapter 5. While the USDA used census tracts as the analysis units, the City of Riverside preferred to use the smaller census block groups and a 500-meter radius from food sources compared to USDA's one-mile radius in urban areas and 10 miles in rural areas. Figure 6-1 shows an overlay map of USDA low food access results using census tracts and results of this analysis showing low food access census blocks. Besides distance and analysis unit used by USDA, the number of 
food sources included in the analysis were limited to just supermarkets and large grocery stores. Other differences in the results may have been because of the data used.

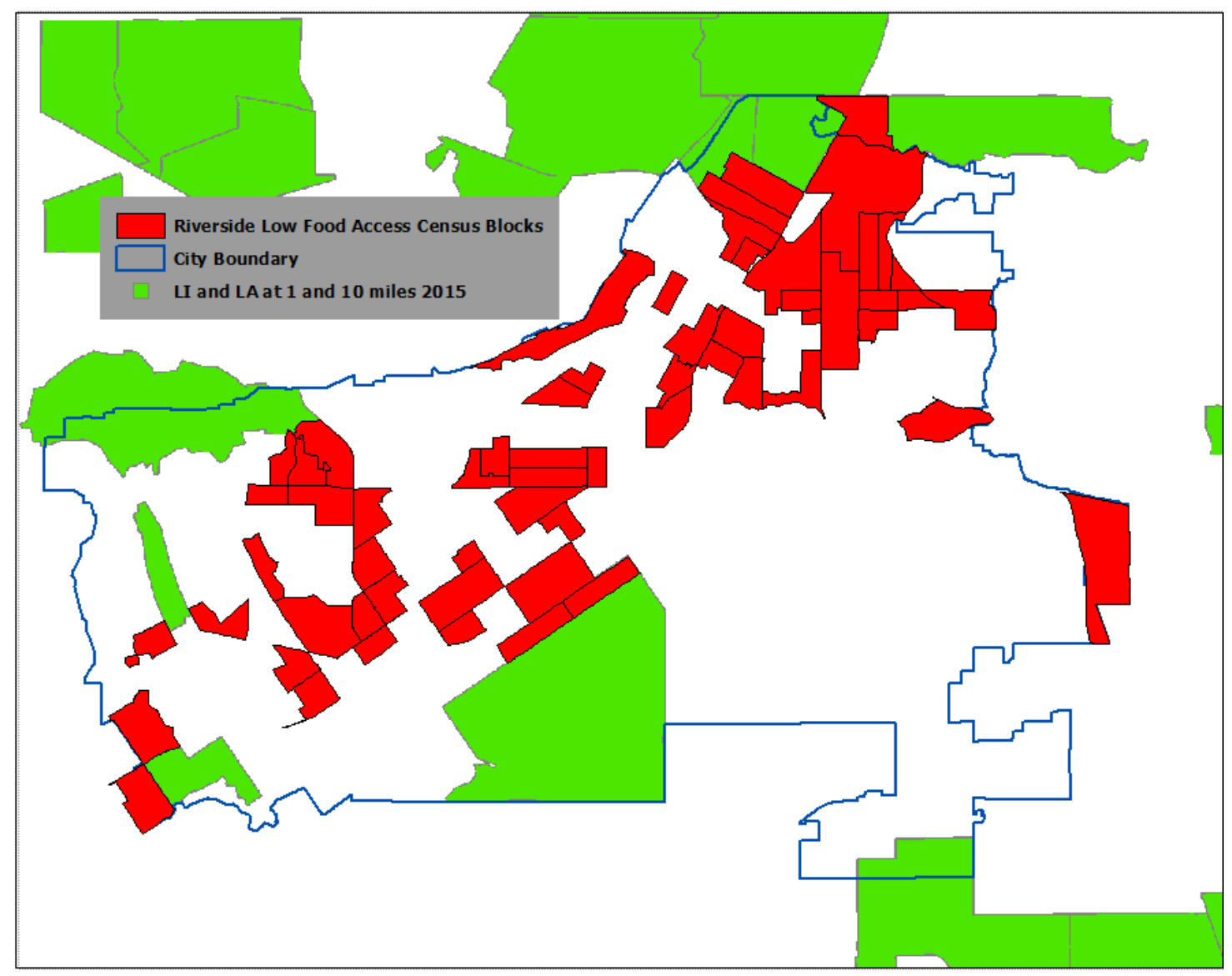

Figure 6-1: The Overlay of USDA Low Income (LI) \& Low Access (LA) Census Tracts (green) and Riverside Low Food Access (red) Analysis Results. Data Source: USDA Economic Research Service.

The City of Riverside sanctioned this analysis to compare results with previous results carried out by the USDA and other researchers. These studies were conducted at a national level and census tracts were used as the smallest analysis units. This analysis identified new areas as food deserts that had been missed in previous studies. The results also demonstrated the importance of cities to conduct their own analyses at a smaller scale to identify areas with low healthy food access. Policy makers, private and public 
stakeholders inclined towards improving access to healthy and affordable food now have a tool to help them channel support to the right recipients, i.e. low-income population who have low access to healthy food (USDA, 2011). Some federal programs that are geared towards improving food access among the poor include Supplemental Nutrition Assistance Program (SNAP), Women Infants, and Children (WIC), The Emergency Food Assistance Program (TEFAP), etc. There are also local non-governmental initiatives that could use this information including Healthy Eating Active Living (HEAL), a local program managed by Kaiser Permanente to promote healthy eating to combat obesity among the socio-economically challenged section of the population (City of Riverside, 2017). Figure 6-2 shows the number of people per square mile living in food deserts.

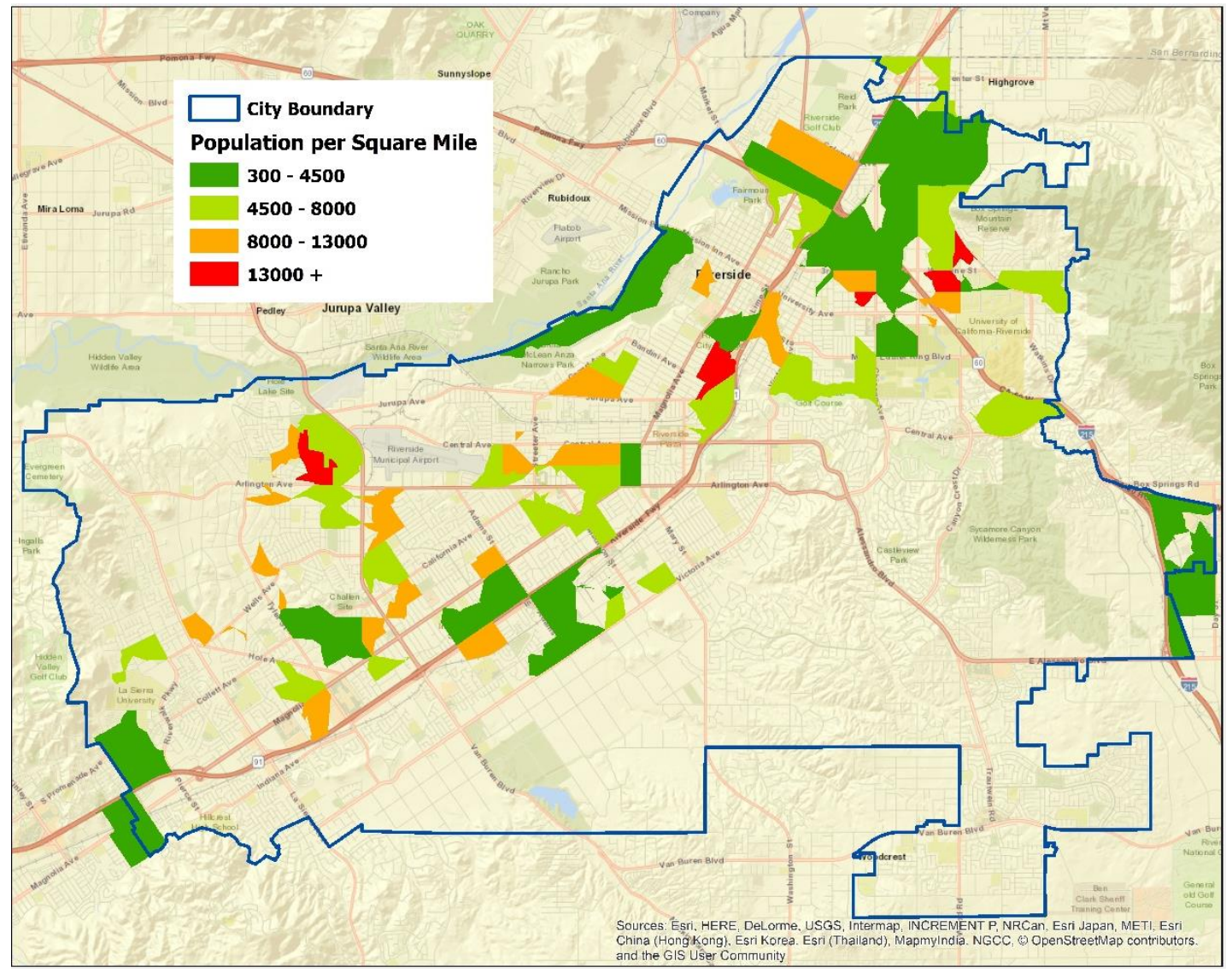

Figure 6-2: City Residents Affected by Food Deserts. 
Food deserts in Riverside were identified as areas that do not have access to a food source within 500-meter radius. The food sources used in this analysis include farmers markets, supermarkets, grocery stores, corner stores, food pantries and farm stands. Figure 6-2 shows map areas that have acute low food access visualized according to the number of residents per square mile affected. A few areas in the northern region of the city shown in red have relatively the most densely populated areas. The most affected areas include the north east, central, and western regions of the city. 19\% of the city residents not only live outside walking distance from food sources but also face socioeconomic challenges. The inability to own a car or afford fare to board public transport further compounds these challenges limiting the poor from moving around in search of stores that provide healthy food options. Households provide information about the number of family units or groups of people living together under one roof. Dealing with households instead of individuals provides an easier alternative for parties interested in alleviating limited food access. Figure 6.3 shows food deserts and the number of households affected per square miles. $20 \%$ of all the households in the City of Riverside live in food deserts. 


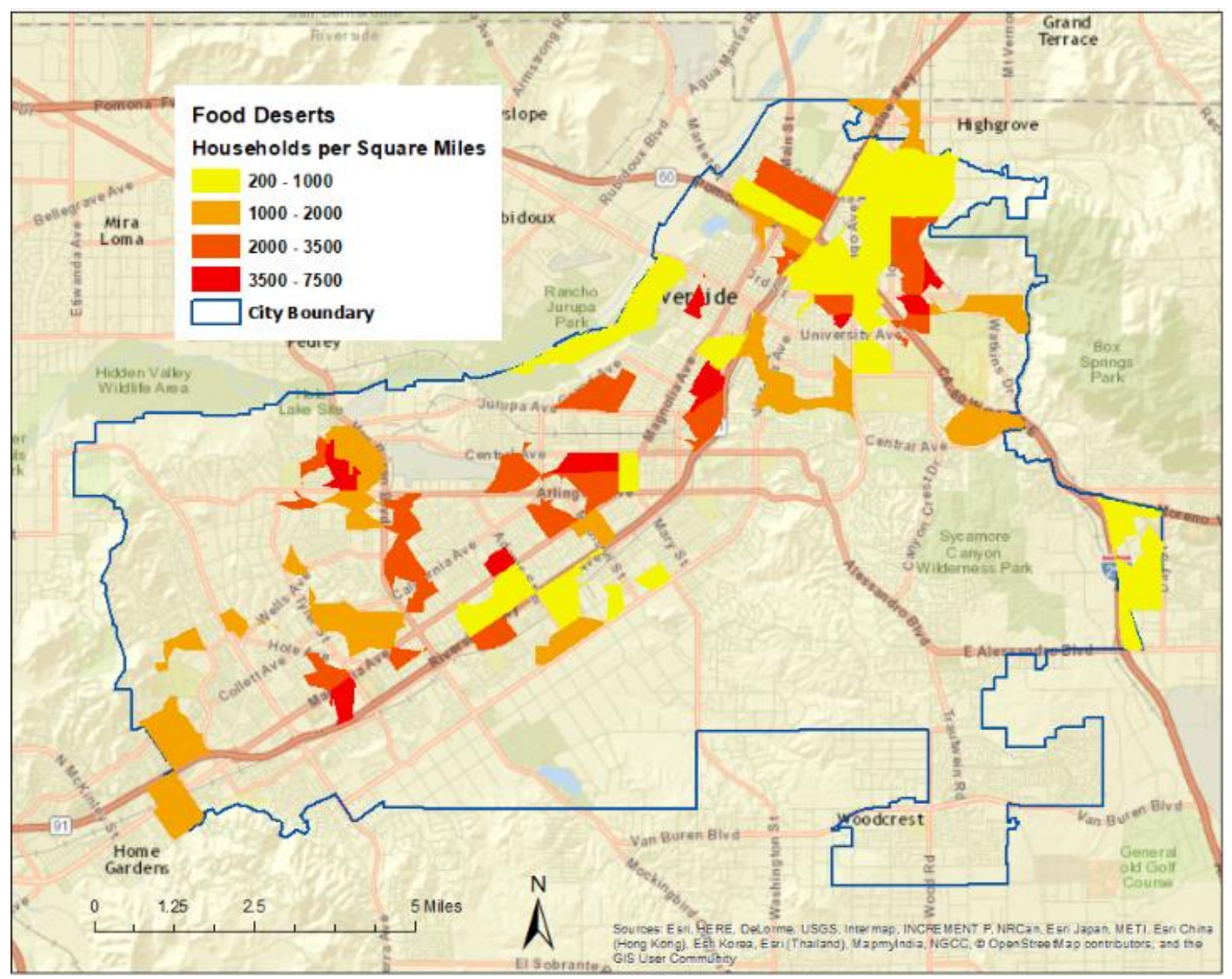

Figure 6-3: Households Living in Food Deserts.

\subsection{The Web Application}

The main goal of this project was to create an interactive online web tool to map the City of Riverside food resources and establish the spatial distribution of healthy food sources using spatial analysis. The final product was expected to replace the existing static map shown in Figure 6.4. Organizing these resources into one repository would make better visualization of food resources and non-spatial information such as contact, web links, working hours, etc. The key functionalities of the application include; the ability to toggle layers on and off, map navigation tools such as zoom and home buttons, basemap toggle, search bar, information window, a dialogue window that provides key information about 
each layer and web links. All these functionalities enhance user experience, i.e. the user can intuitively interact with the application. 


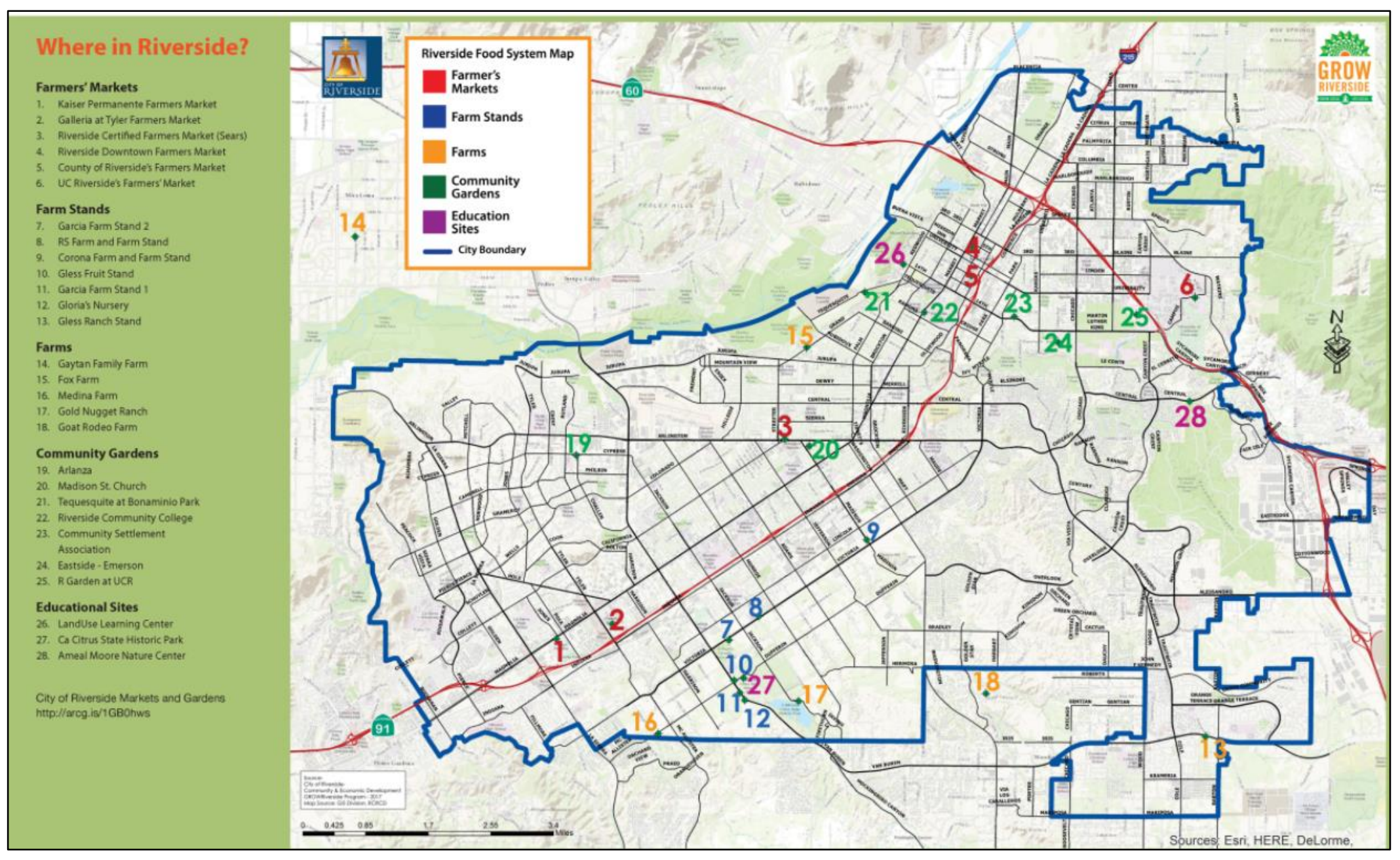

Figure 6-4: The Existing Static Riverside Food System Map. 
The expandable menu on the left section of the application was key to organizing resources and guiding users to better understand and interpret information displayed on the map. The four categories on this menu were purposely given easy-to-interpret names to enable users to find desirable layers under each category. Figure 6.5 shows the web application interface and its various components. Simple pin legend symbols were selected to prevent overcrowding the map when several layers are displayed at the same time. The application was tested on multiple web browsers including Safari, Explorer, Chrome, Firefox, and Opera. All these browsers successfully visualized all the layers and their legend symbols except, Explorer which only loaded legend symbols for the accordion child menu that opens the first time the application is loaded. This was identified as a compatibility issue.

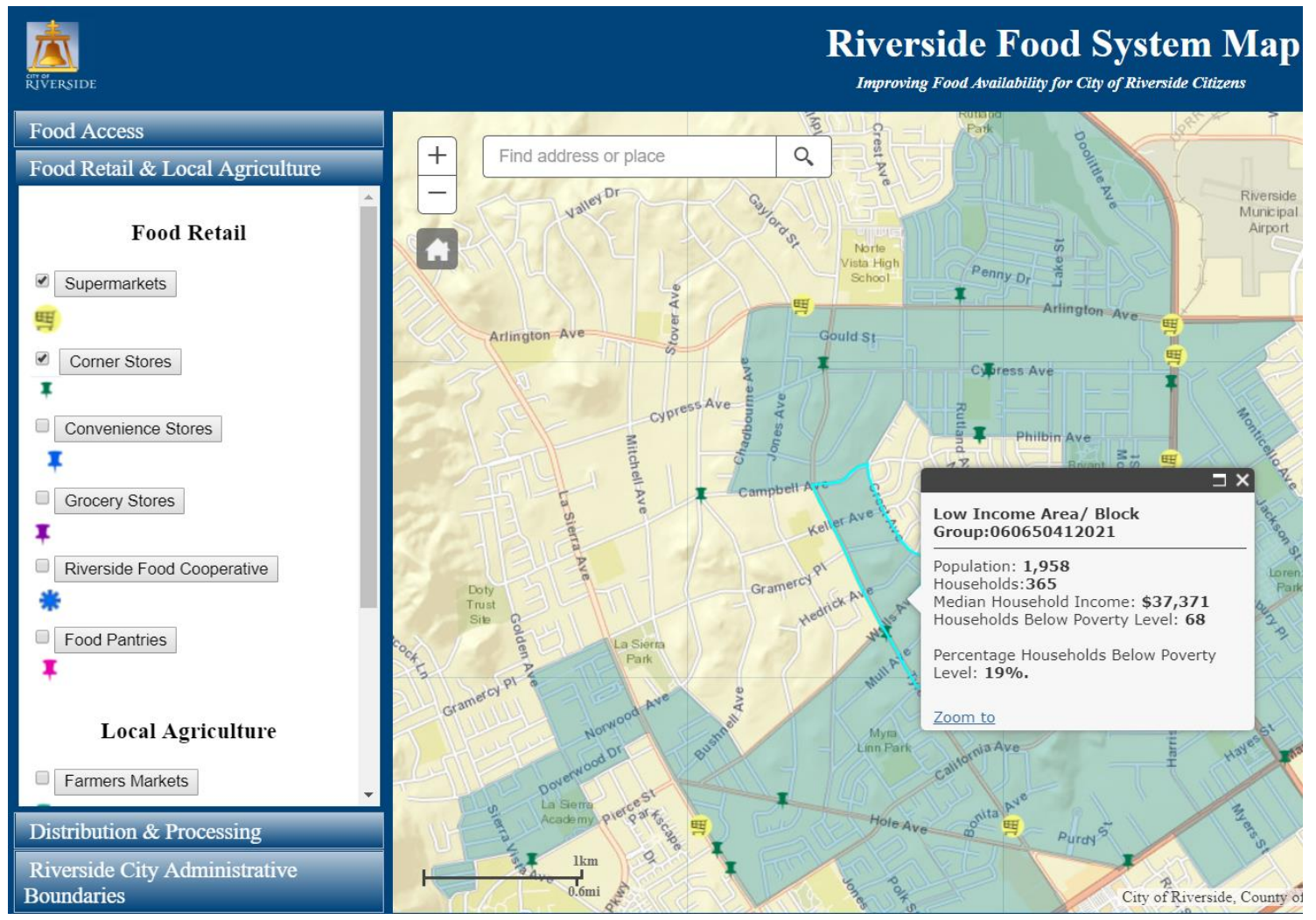

Figure 6-5: Application Interface Showing Accordion Menu and Other Features. 


\subsection{Use Cases}

The web application was designed to enable interaction between stakeholders in the food industry including consumers, food distributors, policy makers, and non-governmental organizations that champion for the improvement of healthy food access, etc. Two unique user cases will be discussed to demonstrate the utility of the application. The application can be easily navigated by non-GIS professionals.

One of the main targets of the food accessibility analysis were policy makers. The City of Riverside comprises seven wards represented by elected council members who make city policies. This is achieved through a collaborative working relationship with city residents. Suppose a scenario during one of the council meetings where a motion is tabled to prioritize the allocation of funds in the city to improve healthy food accessibility through training community members to start community gardens in their backyards. If these funds are only available on need basis, this application can be used by ward representatives to argue why their wards would require immediate attention for such a program. By turning on both the wards and food deserts layers on the application, the council member for Ward 1 can illustrate that there exist large portions within the ward that have low food access as illustrated in Figure 6.6. In this scenario, the web application helps drive key decision-making processes to correctly prioritize and address limited food access. Other city staff could also use this map to solicit support for communities living in food deserts from non-governmental organizations that help alleviate hunger and poor feeding habits. 


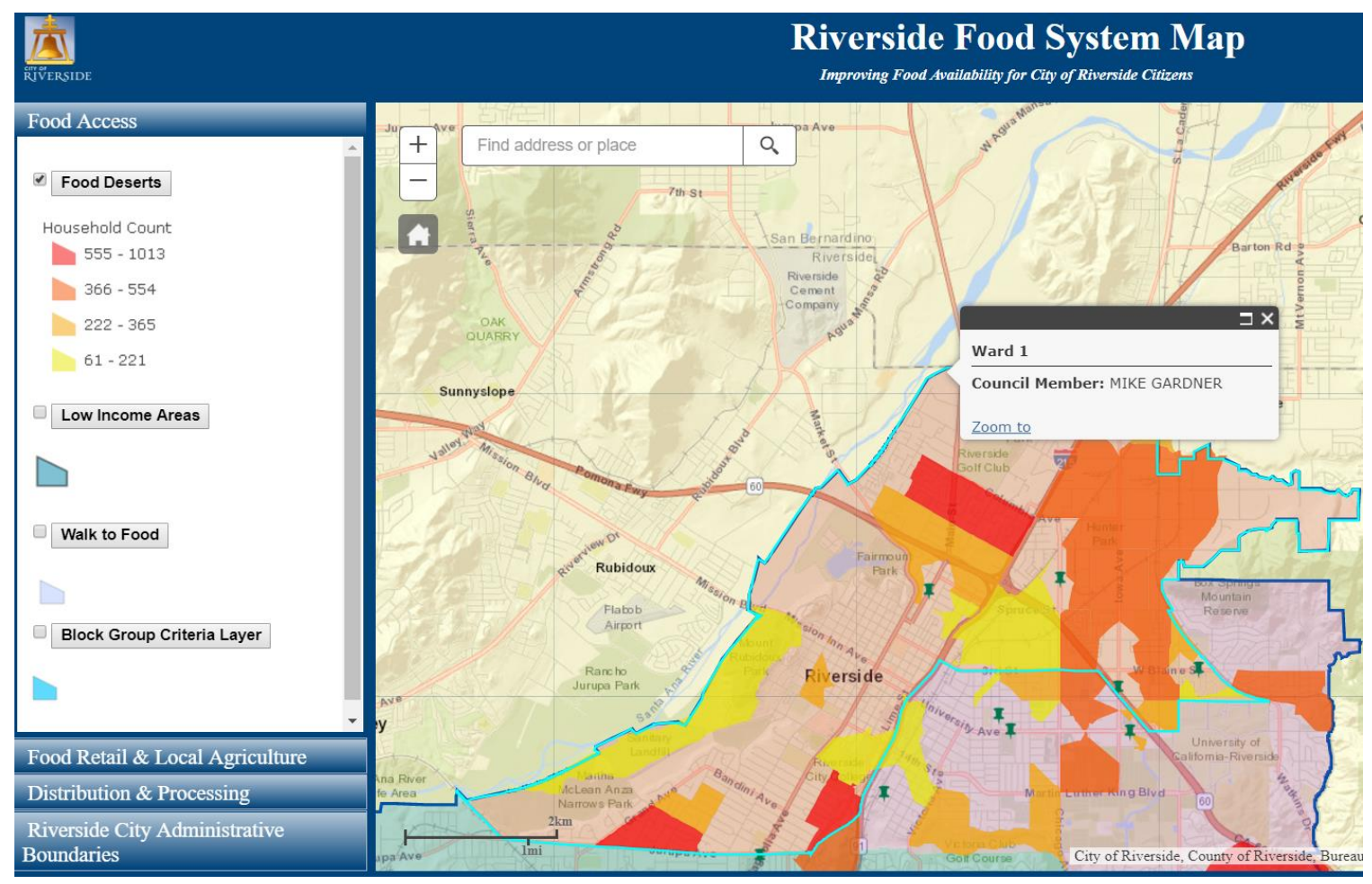

Figure 6-6: Ward 1 Low Food Access Situation.

In another user scenario, a new resident who has just moved to Riverside from a different city or state could use this application to explore the various healthy food sources available in the city. The new resident could locate key fresh local food sources such as farmers markets or farm stands, and crucial information about them such as operating hours as demonstrated in Figure 6.7. The website link on the information window could be useful to the user if they would like to find out more information about a source from their website such as promotions or special offers. This case demonstrates how the application can be an interactive platform to connect consumers and food distributors. The new resident not only promotes the local economy but also benefits by accessing healthy food from the various source options available on the map. Another closely related case would be a user intending to explore various food pantries available 
to get the necessary assistance. The user would need to navigate to the "Food Retail and Access" menu to access the food pantry layer. Each food pantry feature on the map contains a link to the individual website besides the basic information provided on the pop-up window.

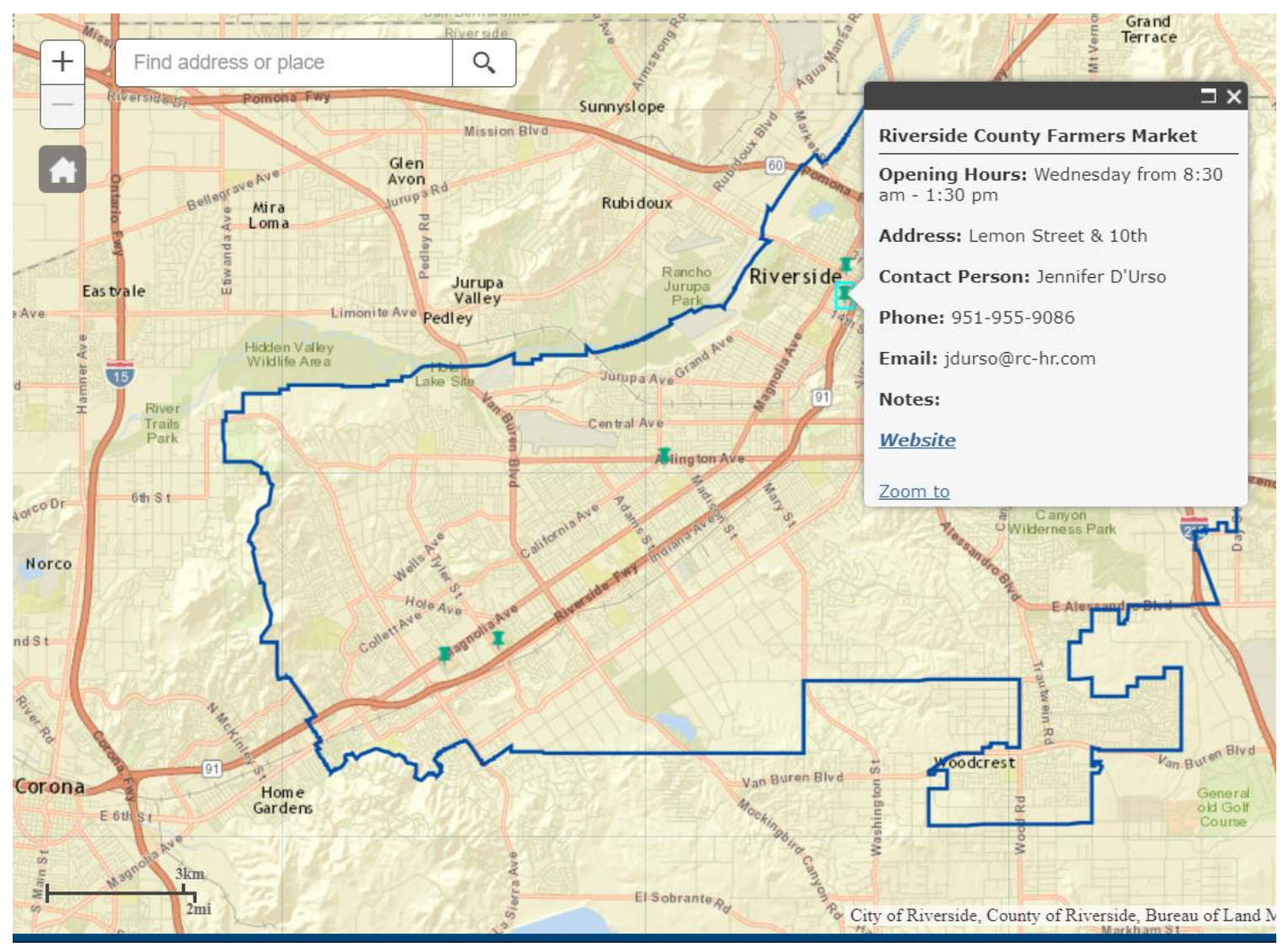

Figure 6-7: Pop-up Window Providing Key Non-Spatial Information to a User.

\subsection{Limitations of the Project}

There were a few limitations identified during the implementation of this project.

Users should also be advised to verify from other more credible data sources available before using the web application data to make key decisions. This includes but is not limited to the food accessibility and food desert analysis results. 
One of the major assumptions for the food desert analysis was the assumption that the population is evenly distributed across a block group. This does not completely represent the true situation in a real-world setting and the problem is exaggerated where some parts of the block group are inhabitable or non-residential. For this reason, some of the 500-meter service areas created using the Network Analyst in ArcMap could have completely missed where people live.

Data from neighboring cities for food sources were not used to solve edge limitations of this analysis whereby residents living at the edges of the city could access food across the boundary. Some sources that provide healthy food were also excluded from the analysis. For example, in other studies or cities, community gardens are regarded highly to improve food access. In this study, the food desert analysis did not take into consideration actual food source capacity based on annual sales volume. There was also a possibility that some food sources may have been omitted from the analysis because they were not captured in the database created. The frequency of a food source in replenishing its healthy food varieties on the shelves is another factor that was missed in the analysis despite being a critical food access factor.

The analysis process to identify food deserts relied mainly on income and distance from a food source. In general, one's financial capacity plays a role in their feeding choices. Most shoppers prefer to shop in more than one places, a status enjoyed by car owners. In food deserts, a sizeable part of the population has both financial capacity and means to reach to a food store. It is difficult to have a food store within walking distance of every residential neighborhood. However, mixed land use practices in urban areas helps to alleviate this problem. It is therefore critical to incorporate extensive factors of 
the consumer in food desert studies to improve accuracy of analysis results. Previous studies related to food access have adopted many different definitions for food deserts. This makes it difficult to adopt a standard criterion for locating food deserts. As a result, there exists no concrete benchmark for food desert studies.

Generally, the web application was designed to be easy to use. However, a user may find it tedious to open different menus to toggle layers on and off due to their placement in different child accordions that only open one at a time. This may be time consuming especially if the user must keep opening the menus to reveal and view layer legends for different features displayed on the map at the same time. When many layers are turned on, the application could get overcrowded limiting user interpretation of data. In such a case, some layers may take too long to display or fail completely, hence hindering desirable user experience.

\subsection{Summary}

Chapter 6 was a summative analysis of the results and utility of the deliverables to the client. Locating food deserts was noted as a key step in alleviating low food access in low-income neighborhoods in a concerted effort between policy makers, nongovernmental organizations and residents through healthy feeding or hunger-fighting programs. The utility of the web application to the users was also discussed through user cases and the benefit a user would gain from using the application. The chapter ended by discussing the limitations of the analyses and the web application. 



\section{Chapter 7 - Conclusions and Future Work}

The chapter is a summary of this project and possible future work to enhance or provide different perspective on the scope of food access.

\subsection{Summary}

This project was undertaken to develop a web-mapping repository of the City of Riverside food resources and analyze food accessibility using spatial data. The project deliverables were provided to the client in the form of a customized web application and analysis maps to enable users to explore the data through the internet. These information products were developed based on the study of similar projects conducted elsewhere and client specifications.

The project began by defining project requirements through meetings and discussions with the client and faculty at the University of Redlands. Data acquired from the client and other sources were geocoded and organized in a file geodatabase. These data were used to create food resource maps and conduct food accessibility analysis using ArcGIS for Desktop \#10.4.1. Food deserts were then identified through multi-criteria analysis that involved income and a one-mile distance from healthy food sources. The analysis results and food resources layers were published to ArcGIS Online as hosted feature services for consumption by the web application.

The web application interface was created using JavaScript, Dojo toolkit, HTML5 and CSS3 languages. Different functionalities such as data querying, toggling layers on and off, zooming and panning maps and basemap toggle were enabled to enhance user experience while interacting with the application. The application was tested to ensure 
that it was supported on common web browsers such as Chrome, Explorer, Firefox, Safari, and Opera.

\subsection{Future Work}

The project requirements were achieved according to client specifications. However, extra work could be conducted to build on the analysis results as well as the web application. The following are recommendations for future work:

- Food access challenges are dynamic depending on study area. It would be interesting to conduct similar research in Kenya to examine what constitutes a food desert in a heavily agricultural economy.

- Food sources differ in capacity to stock healthy food, number of operation hours in a week, and sometimes access privileges are restricted to a few people. These attributes change the discourse on food access. In future research, an overlay weighted analysis could be conducted with each food store assigned weight depending on its capacity, access restrictions and operating hours.

- The web application developed and analysis results could be enhanced in many ways. It would be interesting to focus the food desert analysis on food sources that accept federal food stamps and a comparison of the two results. This is because these stores not only serve as healthy food but also remain sensitive to customers who may not afford to purchase from them. The food desert analysis could also be rerun to include more variables besides income and distance from food sources. The web application could be improved in future by adding editing functionalities to allow the public to update information about food sources. In future, the application could be upgraded to include a functionality that allows 
users to download the data and carry out independent research. Configuring the web application to support access on mobile devices would enhance usability. 



\section{Works Cited}

Alesheikh, A., Helali, H., \& Behroz, H. (2002). Web GIS: Technologies and Its Applications. Symposium on Geospatial Theory, Processing, and Applications. Ottawa.

Ali, M., Park, J., Thiem, V., D., Canh, G., Emch, M., \& Clemens (2005). Neighborhood size and local geographic variation of health and social determinants. International Journal of Health Geographics, 4(12). Doi:10.1186/1476-072X-412

Beaulac, J., E. Kristjansson, \& S. Cummins (2009). A systematic review of food deserts, 1966-2007. Preventing Chronic Disease, 6 (3), A105-A105.

Bhattarai, G., Duffy, P., A., \& Raymond, J. (2006). Use of food pantries and food stamps in low-income households in the United States. The Journal of Consumer Affairs, 39(2): 276-298. doi: 10.1111/j.1745-6606.2005.00015. x.

Brewer, C., A. (2016). Designing Better Maps. A Guide for GIS Users (2 ${ }^{\text {nd }}$ Ed.). Redlands, California: Esri Press.

California Department of Finance, (2016). New State Population Report: California Grew by 348,000 Residents in 2015 . Retrieved on July 26, 2017, from http://dof.ca.gov/forecasting/demographics/estimates/E-1/documents/E1_2016PressRelease.pdf

City of Riverside (2017). HEAL (Healthy Eating Active Living) Zone. Retrieved on July 25, 2017, from https://www.riversideca.gov/park_rec/programs-sports/healthwellness/heal-healthy-eating-active-living-zone 
Collett, S. (2014). Consultative Group on International Agriculture Research (CGIAR): A map application developed with scientific crowdsourcing, identifies priority areas for crops. Retrieved on June 24, 2017, from http://www.computerworld.com/article/2598510/enterpriseapplications/cgiar.html

Dai, D., \& Wang, F. (2011). Geographic disparities in accessibility to food stores in southwest Mississippi. Environment and Planning B: Urban Analytics and City Science, 38: 659-677. doi:10.1068/b36149.

Eckert, J., \& Komuniecki, P. (2010). How urban planning can strengthen Toledo's local food system. Retrieved on April 29, from https://etd.ohiolink.edu/rws_etd/document/get/toledo1271266072/inline

Ericksen, P., J. (2008). Conceptualizing food systems for global environmental change research. Global Environmental Change 18, (1), 234-245. Doi: org/10.1016/j.gloenvcha.2007.09.002

Esri (2017). ArcGIS Server: What is a Feature Service? Retrieved on July 18, 2017, from http://server.arcgis.com/en/server/latest/publish-services/linux/what-is-a-featureservice-.htm

Food, Conservation, and Energy Act of 2008, H.R. 6124, 110th Congress. (2008)

Fu, P. (2016). Getting to Know Web GIS (2 ${ }^{\text {nd }}$ Ed.). Redlands, California: Esri Press. Fu, P., \& Sun, J., (2011). Web GIS: Principles and Applications. ( ${ }^{\text {st }}$ Ed.). Redlands, California: Esri Press. 
Galzki, J. C., Mulla, D. J., \& Peters, C. J. (2014). Mapping the potential of local food capacity in Southeastern Minnesota. Renewable Agriculture and Food Systems, 30(4), 1-9. doi.org/10.1017/S1742170514000039

Hannah, V. et al. (2012). Food System Assessment. Retrieved on July 26, 2017, from https://akfoodpolicycouncil.files.wordpress.com/2013/07/2012-food-systemassessement-final-report-11_19_12.pdf

Hallet IV, L., \& McDermott (2011). Quantifying the extent and cost of food deserts in Lawrence, Kansas, USA. Applied Geography, 31(4), 1210-1215. Doi: 10.1016/j.apgeog.2010.09.006

Herries, J. (2010). Mapping food deserts [PowerPoint slides]. Retrieved on July 18, 2017, from https://s3.amazonaws.com/webapps.esri.com/esriproceedings/healthy-communities10/pdfs/mapping-food-deserts.pdf

Huang, C., \& Pike, L., (2016). The Green and Smart Urban Development Guidelines provide a simple yet high-quality formula to set a new default for Chinese cities. Retrieved on September 10, 2017, from https://www.connect4climate.org/article/12-design-principles-new-urban-default

Jioa, J., Ulmer, J., Hurvitz, P., Drewnowski, A. \& Moudon, A. (2012). How to identify food deserts: measuring physical and economic access to supermarkets in King County, Washington. American journal of public health, 102(10) e32-e39. doi: 10.2105/AJPH.2012.300675

Johns Hopkins Centre for a Livable Future (2017). [A Web-mapping Application of Downloadable Food Systems, Public Health, and Environmental Data]. Maryland 
Food System Map. Multiscale. Retrieved on July 12, 2017, from https://gis.mdfoodsystemmap.org/map/

United States Department of Agriculture. Know Your Farmer, Know Your Food Compass Map, KYF Compass Map [Online Map]. Multiscale. Retrieved January 4, 2017, from https://www.usda.gov/wps/portal/usda/usdamedia?navid=kyfcompass-map

Kuai, X., \& Zhao, Q. (2017). Examining healthy food accessibility and disparity in Baton Rouge, Louisiana. Annals of GIS, 23(1) 1-14. doi:10.1080/19475683.2017.1304448

Luo, W., \& Wang, F. (2003). Measures of spatial accessibility to health care in a GIS environment: synthesis and a case study in the Chicago region. Environment and Planning B, 30 (6): 865-884. doi:10.1068/b29120.

Martinez, S., et al. (2010). Local food systems; concepts, impacts, and issues. Retrieved on January 6, 2017, from https://www.ers.usda.gov/webdocs/publications/46393/7053_err97_reportsummar y_1_.pdf?v=42265

Michimi, A., \& Wimberly, M. (2010). Associations of supermarket accessibility with obesity and fruit and vegetable consumption in the conterminous United States. International Journal of Health Geographics, 9: 49.doi:10.1186/1476-072X-9-49.

Persaud, H. (2013). Monitoring Community Health Using a Web-Based GIS Application (Master's thesis, University of Redlands). Retrieved from http://inspire.redlands.edu/gis_gradproj/200 
Ploeg, M., Dutko, P., \& Breneman (2014). Measuring food access and food deserts for policy purposes. Applied Economic Perspectives and Policy, 37 (2), 205-225. Doi: org/10.1093/aepp/ppu035

Ploeg, M., \& Rhona, A., (2017). Food Access Research Atlas Documentation. Retrieved on September 14, 2017 from https://www.ers.usda.gov/data-products/food-accessresearch-atlas/documentation.aspx

Schmelzkopf, K. (1995). Urban community gardens as contested space. Geographical Review, 85(3), 364-381. doi:10.2307/215279

Spence, J., Cutumisu, N., Edwards, J., \& Evans, J. (2008). Influence of neighborhood design and access to facilities on overweight among preschool children. Pediatricobesity, world obesity, 3(2), 109-116. doi: 10.1080/17477160701875007

Tomlinson, R. (2013). Thinking About GIS (5 ${ }^{\text {th }}$ Ed.): Geographic Information Systems for Managers. Redlands, California: Esri Press.

USDA (2009). The What and Why of Local and Regional Foods. Retrieved on June 30, 2017 from https://www.usda.gov/sites/default/files/documents/1-Whatandwhy.pdf USDA (2010). USDA Defines Food Deserts. Retrieved on June 30, 2017, from http://americannutritionassociation.org/newsletter/usda-defines-food-deserts

USDA (2011). Food Desert Locator. Retrieved on July 24, 2017 from https://www.fns.usda.gov/tags/food-desert-locator

Walker, R., Keane, C., \& Burke, J. (2010). Disparities and access to healthy food in the United States: A review of food deserts literature. Health and Place, 16(5), 876884. doi: 10.1016/j.healthplace.2010.04.013 
Wang, F., \& Luo, W. (2005). Assessing spatial and non-spatial factors for healthcare access: towards an integrated approach to defining health professional shortage areas. Health \& Place, 11 (2): 131-146. doi: 10.1016/j.healthplace.2004.02.003 


\section{Appendix A. Sample HTML Code}

This is part of the HTML code that was written in JetBrains WebStorm 2016.3.3.

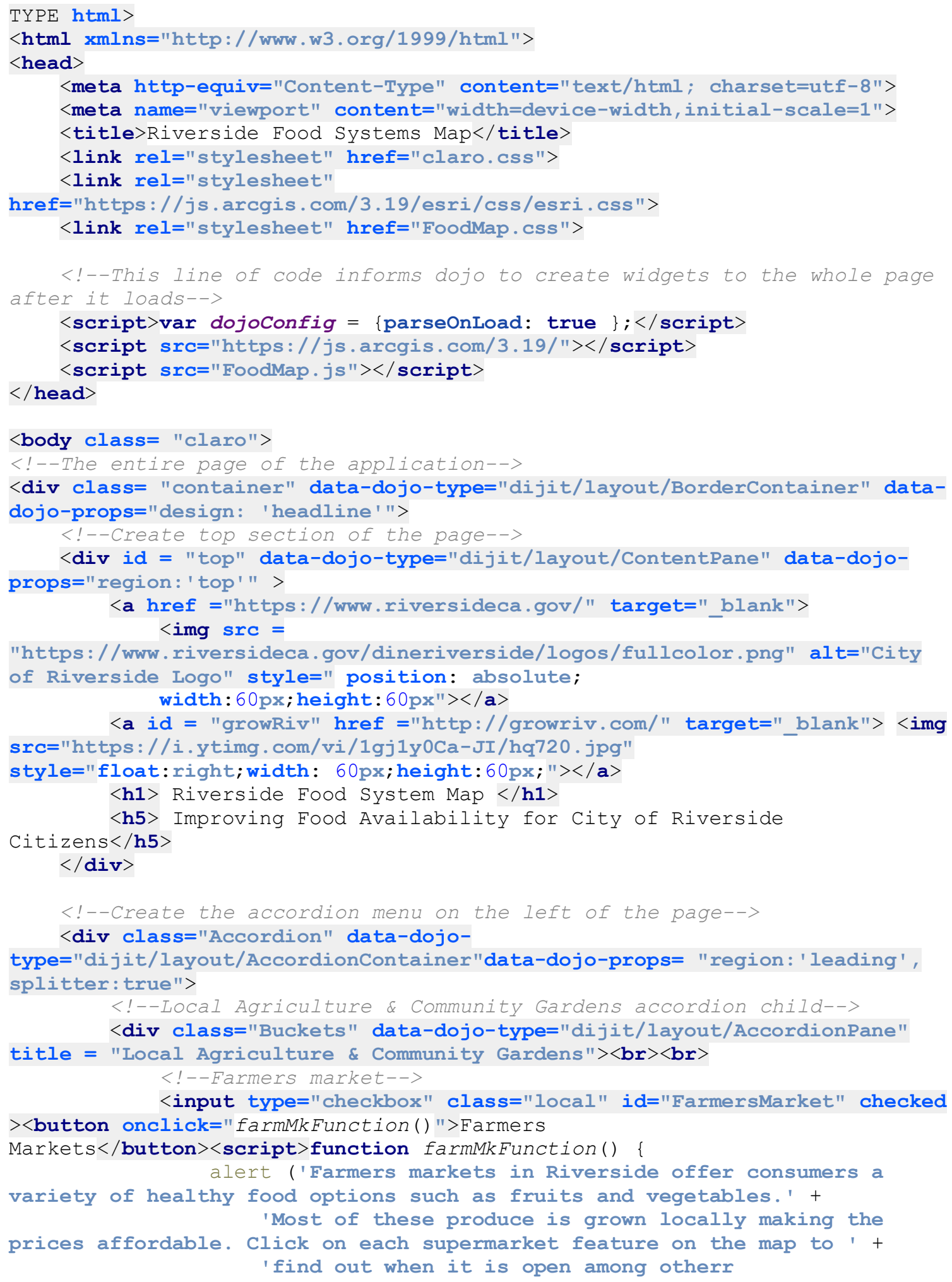




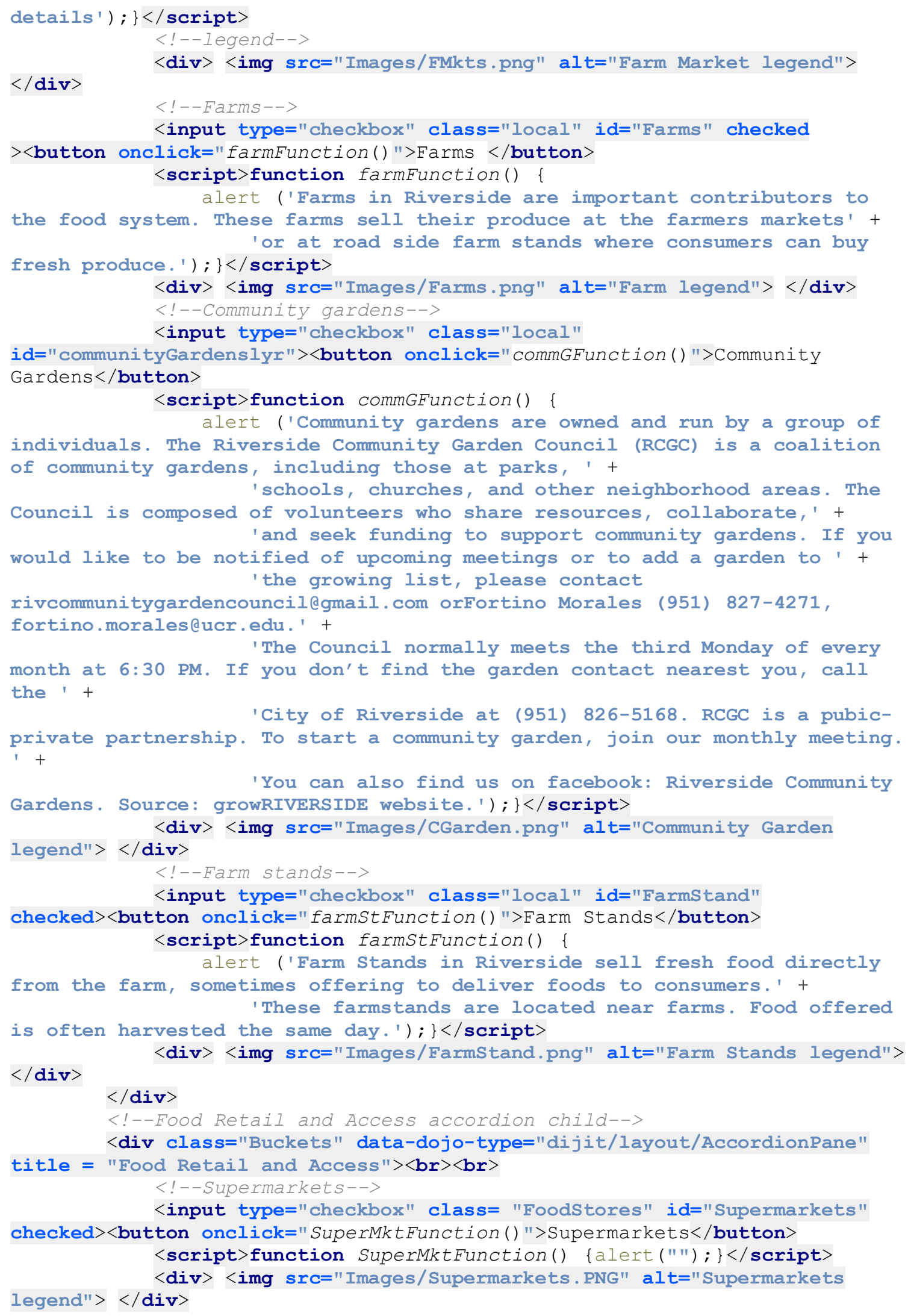




\section{Appendix B: Maps}

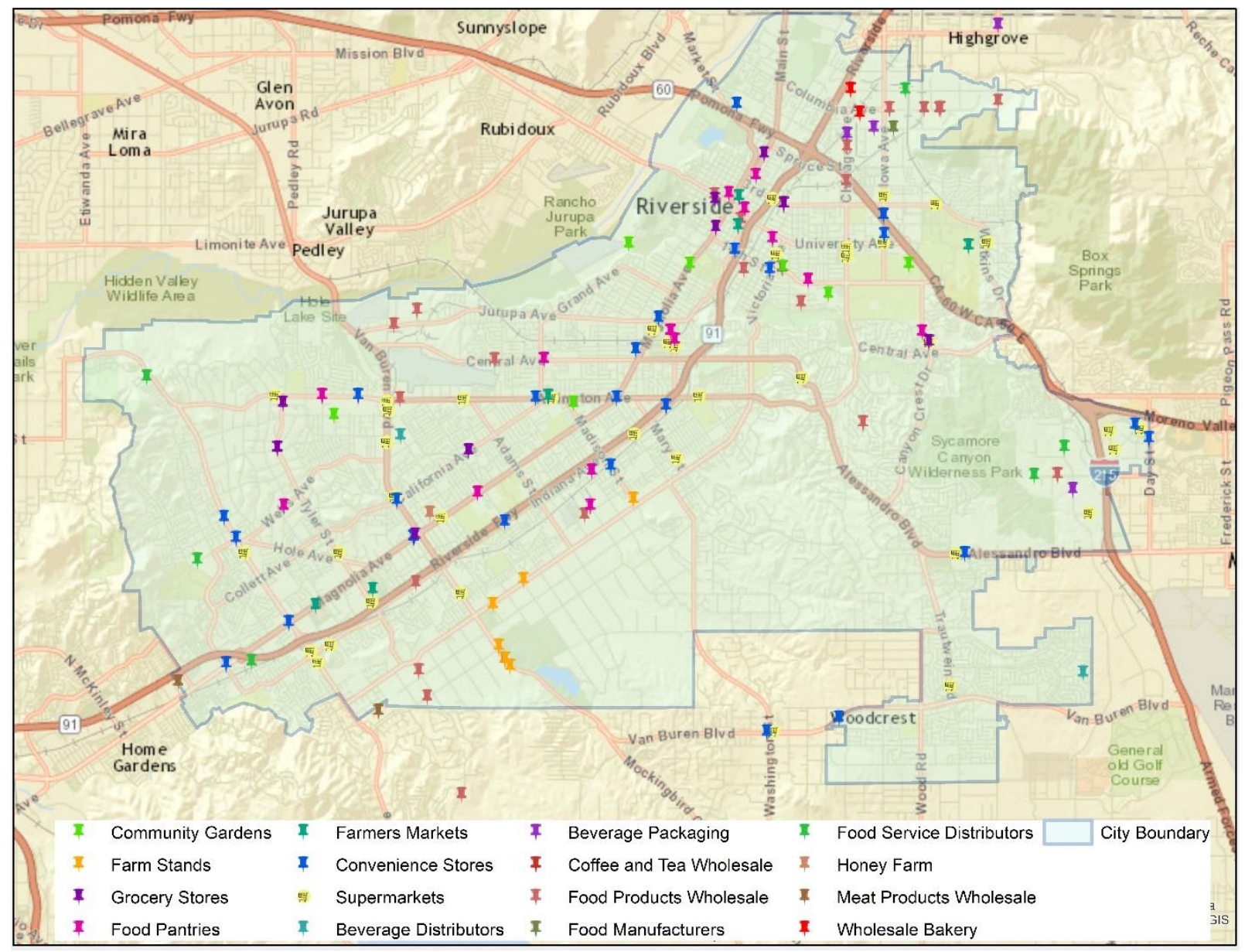

Map 1: The City of Riverside Food Sources 


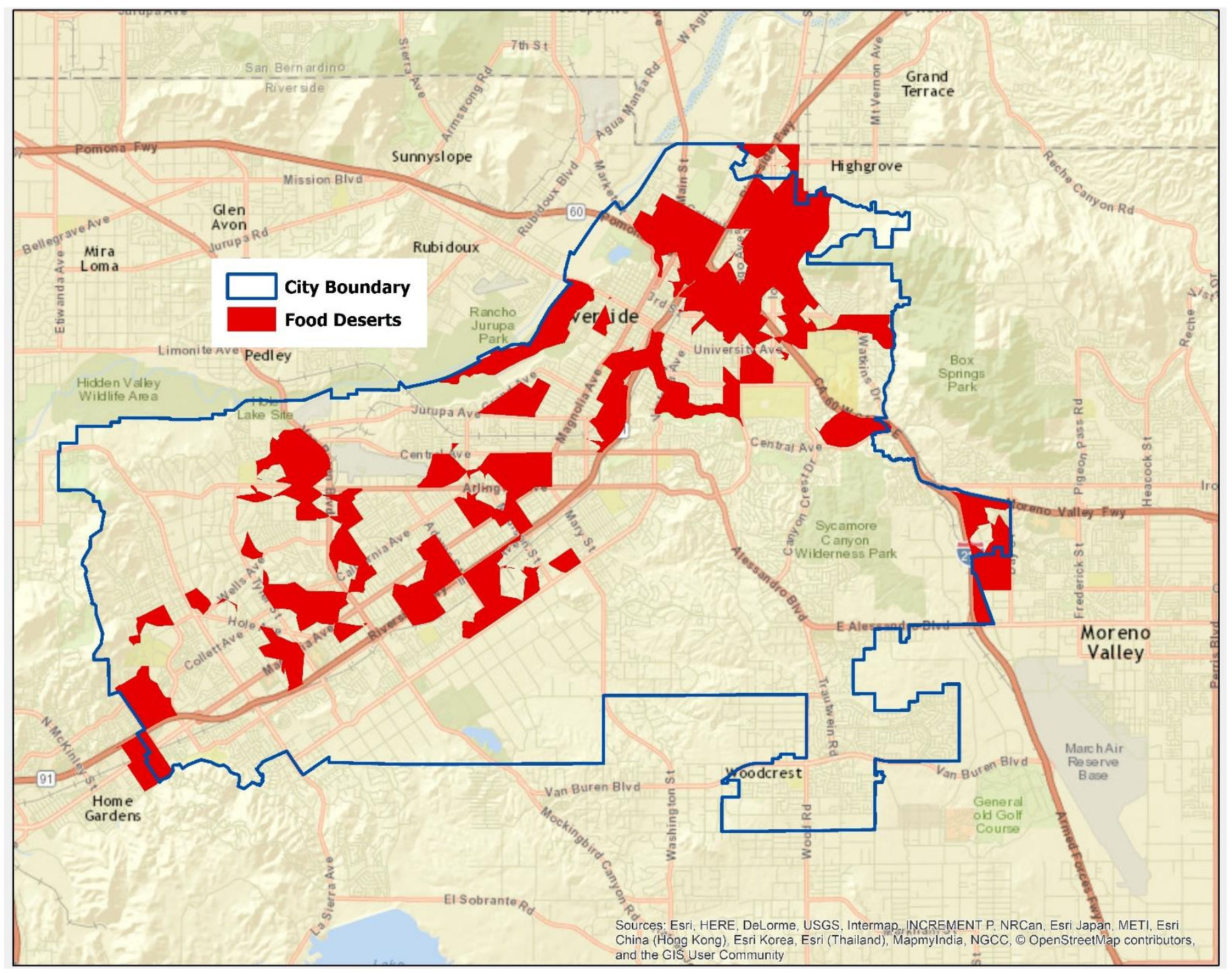

Map 2: Riverside Food Deserts 


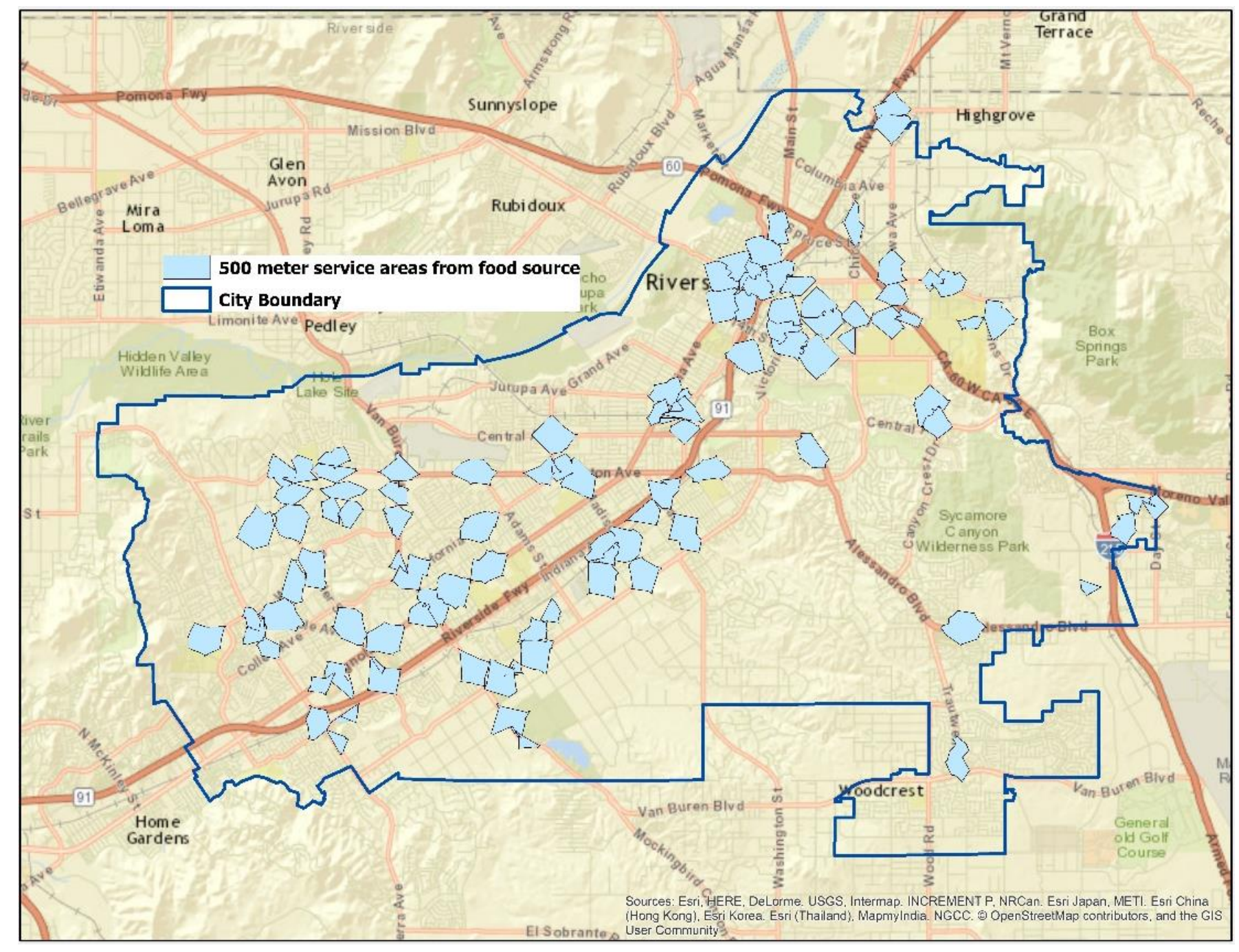

Map 3: 500-Meter Radius Service Areas Around Healthy Food Sources 